\title{
MERCADOS GLOBALES DE LA AMÉRICA ESPAÑOLA: EL COMERCIO DE LANA VICUÑA Y GRANA COCHINILLA EN EL SIGLO XVIII*
}

\author{
GLOBAL MARKETS OF SPANISH AMERICA: \\ THE COMMERCE OF VICUÑA WOOL AND GRANA \\ COCHINEAL IN THE XVIII CENTURY
}

\author{
Manuel Pérez-García \\ Renmin University of China, Beijing, China, manuel.perez@ruc.edu.cn
}

Resumen. El presente artículo analiza la comercialización de la lana de vicuña peruana y la grana cochinilla, principalmente procedente de sierras andinas y Nueva España, y el impacto, durante el siglo XVIII, de la comercialización de productos coloniales pertenecientes al ramo textil en las economías de la Europa mediterránea, especialmente para los casos de Francia y España. La paulatina integración de mercados globales de la América española, como pueden ser los referentes al sector textil, con los de Europa occidental fue un factor clave en la consolidación de redes y rutas de comercio, así como circulación de bienes a un lado y otro del Atlántico.

Palabras clave: mercados globales; lana de vicuña; grana cochinilla; consumo; Marsella.

Abstract. This article analyzes the commercialization of Peruvian vicuña wool and grana cochineal, originating mainly in the Andean highlands and New Spain, and their impact on the commercialization of colonial products pertaining to the textile industry during the XVIII century in the economies of the Mediterranean Europe, especially in the cases of France and Spain. The progressive integration of global markets of Spanish America, such as those pertaining to the textile industry, with occidental Europe was a key factor in the consolidation of networks and commerce routes, as well as the flow of goods from one side of the Atlantic to the other.

Key words: global market; vicuña wool; grana cochineal; consumption; Marseille.

Fecha de recepción: 6 de octubre de 2014. Fecha de aceptación: 24 de marzo de 2015.

* La redacción y principales ideas de este artículo han sido elaborados durante mi pasada estancia, julio-agosto de 2014, como profesor visitante en el Instituto de Investigaciones Dr. José María Luis Mora, ciudad de México, en donde parte de mi estancia fue financiada por el programa de becas de profesores visitantes de la Secretaría de Relaciones Exteriores de México. Muestro mi más sincero agradecimiento a los profesores Luis Jáuregui y Antonio Ibarra por acogerme tan amablemente en el Instituto Mora y en la Universidad Nacional Autónoma de México (UNAM) en el Seminario Interinstitucional de Historia Económica del Colegio de México/UnAM/ Instituto Mora, a los profesores Bernd Hausberger, Guillermina del Valle Pavón, Sandra Kuntz, 


\section{INTRODUCCIÓN}

7 ras la guerra de Sucesión y especialmente durante la segunda mitad del siglo XVIII, la economía española era parcialmente dependiente de la participación extranjera en el comercio, hecho que se demuestra con la llegada a territorio castellano de familias de comerciantes extranjeros, principalmente franceses, durante el siglo XVIII (Lemeunier y Pérez, 1990, pp. 113-114; Salas, 2009, pp. 214-224). El comercio con Marsella adquirió notoria importancia durante esta centuria, cuya característica principal era las exportaciones de materias primas, en algunos casos mercancías parcialmente elaboradas como la grana, a cambio de la importación de manufacturas procesadas con esos mismos productos. Ante un comercio de creciente importancia, y de acuerdo con los datos y el material empírico que presentamos en este artículo, tales actividades mercantiles dinamizaron el comercio marsellés además del relativo a las colonias americanas.

El principal tema de este artículo es el análisis de productos coloniales específicos pertenecientes al ramo textil distribuidos por el grupo de comerciantes marselleses que establecieron sus negocios en los puertos de la España mediterránea y la América española. El estudio de las exportaciones de lanas, como la lana vicuña, y productos tintóreos procedentes de las colonias americanas es de gran importancia para observar cómo tal actividad mercantil tuvo a largo plazo efectos negativos en la balanza de pagos española. Igualmente, desde el siglo XVI, la importación masiva de lanas y tintes americanos tuvo un notorio impacto en las pautas de consumo, pues se crearon tendencias en las modas y consumo de textiles debido al brillo de los colores que las prendas adquirían con tintes como la grana cochinilla.

Para este artículo se han utilizado como fuente principal las series estadísticas relativas a los registros comerciales que se encuentran en la Chambre de Commerce de Marseille, las cuales son de gran riqueza, pues permiten observar el comercio internacional entre Francia, España y los territorios del Atlántico. De este modo, las redes comerciales que se tejieron entre los grupos de mercaderes franceses y españoles estaban integradas en un contexto mercantil a escala global. Igualmente, hemos analizado inventarios post mórtem y dotes pertenecientes al Archivo Histórico Provincial de Murcia para ver la evolución del consumo de estos pro-

y muy especialmente al profesor Carlos Marichal que tan amablemente me hizo sugerencias y dio ideas para la mejora de este artículo, aunque cualquier fallo o error son responsabilidad mía. Igualmente agradezco las sugerencias de los evaluadores de este artículo que han contribuido a la mejora y reelaboración del mismo. 
ductos. Dada su relevancia, el puerto de Marsella podría ser denominado como puerta de entrada al comercio con Europa. También era la puerta de acceso a las redes mercantiles francesas que adquirieron el control del comercio mediterráneo. A través de las redes de negocios marsellesas se integraban las rutas comerciales europeas con Oriente, pues se conectaban las caravanas de Levante (Panzac, 2004) y los mercados del Atlántico, que unían el extremo más occidental del Mediterráneo mediante las redes mercantiles de Cádiz. Este hecho resalta el carácter transnacional (Haupt y Kocka, 2009) de Marsella como eje mercantil que igualmente conectaba con los mercados meridionales, centrales y septentrionales de Europa, lo que propició un comercio fluido de bienes asiáticos y atlánticos que circulaban en estos mercados (Braudel, 1979; Carrière, 1973).

En este sentido, el comercio de lana de vicuña peruana, el de la cochinilla y otros tintes como el índigo, influyeron en gran parte en la dinamización y el desarrollo del sector textil europeo y español. Tales tintes eran introducidos en industrias francesas, principalmente en Lyon, Grenoble o Bearn, e italianas, como los centros textiles piamonteses, destacando los de Turín. En las zonas meridionales de Francia y septentrionales de Italia se localizaban los núcleos más importantes de producción manufacturera textil, donde se elaboraban productos con tintes y lanas de las colonias americanas. Desde Marsella, las manufacturas textiles acabadas eran exportadas hacia los puertos mediterráneos de España, en donde las redes de comerciantes franceses que allí ejercían sus negocios, principalmente a través de la casa Roux, importaban igualmente a la región meridional francesa materias primas como la seda, el algodón, la lana y la barrilla. Así, la exportación de materias primas relativas al ramo textil se convirtió en una de las actividades principales de la economía española durante el siglo XVIII.

Los grupos de familias foráneas, que se dedicaban esencialmente a la actividad comercial y negocios, eran los actores sociales principales y fundamentales en la estimulación de las economías regionales de la España mediterránea. Debido al carácter emprendedor de estas redes mercantiles, los mercados locales se integraban en un marco y modelo económico global en el cual otros territorios de la Europa mediterránea, como Italia, Grecia o Malta, eran partícipes activos de este modelo económico que conectaba las economías europeas y americanas. La economía española era altamente especializada en la producción y exportación de materias primas. A ello se debe sumar la falta de un marco económico institucional que permitiese el financiamiento externo en la producción doméstica de bienes textiles acabados, especialmente por los gremios que ponían freno a la innovación y desarrollo de nuevas actividades. Esta conjunción de 
factores hizo que en el medio y largo plazo la producción manufacturera española se situase en un lento proceso de modernización.

Igualmente la inexistencia de una mano de obra preparada y entrenada en la adquisición de nuevas técnicas en la producción textil, sumada a la falta de infraestructuras, fueron los factores que propiciaron que los grupos y redes de comerciantes extranjeros fuesen parte crucial en el engranaje financiero, permitiendo una mayor dinamización de la economía, la cual era altamente dependiente del capital exterior. De ahí que el papel de mayoristas y minoristas en satisfacer las demandas y necesidades que se instalaban en los mercados fuese crucial. Una de las principales causas de este hecho fue la progresiva integración de mercados locales a escala global y la conformación de redes de acaudalados y pequeños comerciantes, así como buhoneros, que ejercieron funciones de distribución, marketing y venta. Este factor fue fundamental en la dinamización y desarrollo de la economía nacional. Como consecuencia negativa de este entramado mercantil en la introducción de bienes de consumo extranjeros, se produjo un saldo negativo en la balanza de pagos española al exceder por norma general las importaciones respecto a las exportaciones. La balanza negativa comercial y la lenta modernización de los sectores manufactureros textiles en España en el siglo XVIII con certeza contribuyeron al crecimiento poco dinámico y competitivo de la economía española de esta época.

Dirigentes gubernamentales y ministros ilustrados editaron y promulgaron medidas mercantiles basadas, sobre todo, en el proteccionismo industrial y la prohibición de entrada de productos extranjeros. El objetivo era, estérilmente, estimular las industrias y producción nacionales, además del consumo de bienes nacionales mediante un férreo control del consumo. El resultado de tales medidas tuvo efectos contrarios a los deseados, puesto que para el caso textil, el uso y adquisición de bienes extranjeros, como pudieran ser los indianos -algodones, lanas y sedas, entre otros bienes-, estaban entre las principales prohibiciones. Sin embargo, la promulgación de estas medidas tuvo efectos opuestos ya que no evitó que tanto comerciantes como consumidores adquiriesen los productos americanos tan deseados por la sociedad del siglo XVIII, provocando que su consumo aumentara, al igual que el comercio ilegal o contrabando (Riello, 2013). Los deseos de estimular la producción nacional, así como las industrias y los pequeños talleres artesanales, quedaron en una aspiración utópica esgrimida, principalmente, por intelectuales y ministros ilustrados.

Ciertamente existían pequeños núcleos especializados en la producción textil, como los relativos al área catalana y núcleos muy localizados de Valencia, Murcia, Almería o Granada, pero esta tímida especialización textil a escala local no provocó un desarrollo a escala nacional en la manufacturación de productos acabados, lo que marcó una clara dependencia 
hacia mercados externos. Por tanto, podemos decir que una de las principales actividades de la economía española era la exportación de materias primas y la importación de manufacturas finalizadas que satisfacían las nuevas demandas del consumidor hacia un tipo de productos más exóticos o que estaban más a la moda, los cuales no podían ser producidos por los obsoletos talleres y gremios artesanales.

\section{Participación marsellesa en mercados de Nueva España y Perú: COMERCIO Y EVOLUCIÓN DEL CONSUMO DE LANA DE VICUÑA Y GRANA COCHINILLA}

Las redes sociales tejidas en torno a las transacciones comerciales, que tuvieron lugar en el área mediterránea y que conectaron Europa con los mercados asiáticos y atlánticos, permitieron que una amplia gama de productos procedentes de estos mercados circulasen con fluidez, además de estimular el consumo. Sin embargo, tal y como mencionábamos en las líneas preliminares, este creciente consumo de productos foráneos tuvo efectos negativos en la balanza de pagos, así como en la capacidad productiva de las industrias y los centros artesanales del territorio español, lo que provocó un retraso en los niveles de desarrollo económico en comparación con otros territorios europeos. España tenía un índice de productividad mucho más bajo que territorios más avanzados del noroeste de Europa tales como Inglaterra o Países Bajos. Estos territorios ejercían una inversión más fuerte en el sector industrial y apostaban por técnicas nuevas de producción, tecnología e innovación que los hicieron despegar económicamente respecto a sus homólogos de la zona más meridional de Europa, como podía ser España. Si a esto sumamos que la zona noroccidental de Europa tenía menos restricciones comerciales, y por tanto unas políticas mercantiles menos rígidas que zonas como la española, se podría decir que el marco económico de zonas como Inglaterra o Países Bajos se aproximaba a los parámetros económicos de las doctrinas smithianas de libre comercio (O'Brien, 2000).

A escala local, la incapacidad productora de los centros artesanales españoles para satisfacer la nueva demanda, tendente hacia nuevas modas, bienestar y adquisición de una mejor calidad de vida, hizo que el comercio y la reexportación de productos transnacionales y transcontinentales generasen un nuevo modelo de consumo. Marsella era el enclave portuario donde se redistribuían tales productos a los núcleos portuarios de la cuenca mediterránea española. Por tanto, España era el territorio europeo hacia donde se distribuía una mayor cantidad de productos asiáticos y atlánticos que llegaban a Marsella, debido a las actividades mercantiles 
de las redes comerciales francesas que tenían un importante volumen de negocios en Asia y en América (véase gráfica 1).

La casa comercial marsellesa Roux-Frères se puede considerar como una de las casas de negocios con mayor relevancia de la Europa mediterránea del siglo XVIII y primera mitad del XIX. Esta casa comercial fue fundada en 1728 y adquirió un importante peso en las transacciones comerciales entre las distintas zonas de Europa, América y Oriente. Pierre-Honoré Roux, nacido en 1695 y fallecido en 1774 , fue su figura principal y quien llevó a la compañía a su máximo apogeo. ${ }^{1}$

El volumen de salida de productos de Marsella hacia España fue mucho mayor respecto a otros países europeos, hecho que se reflejó negativamente en la balanza de pagos. De este modo, el comercio extranjero y el que conectaba con mercados de ultramar, especialmente con los de las colonias americanas, fueron los únicos estímulos que intensificaron de manera coyuntural centros muy localizados de producción artesanal y comercio regional. Las redes sociales y comerciales creadas por los Roux, que se tejían en torno a núcleos rurales y urbanos, especialmente los situados en las proximidades de zonas portuarias, estimularon la economía a escala regional mediante el fomento de estrategias de distribución, marketing y venta. Las transacciones, tanto de lana ovina como de vicuña, crearon redes de comercio en torno a este producto en la vertiente más occidental del Mediterráneo, que conecta con los mercados del Atlántico. La lana era adquirida por la casa mercantil Roux-Frères y redistribuida a los comerciantes de origen francés que tenían asiento en el litoral mediterráneo español, entre ellos Joseph Cayron, natural de Venze; ${ }^{2}$ Pedro Bremon, de Marsella; ${ }^{3}$ Jaime Champeli Pirraimun, de Clemensa, obispado de Tula; ${ }^{4}$ Antonio Churguet Churguet, de la región de Auvergne; ${ }^{5}$ Juan de Orleac o Juan Cayluz, ambos cuñados y maestros caldereros; ${ }^{6}$ Pedro Luis Bridon y su mujer María Barbara Devan Andrés, de origen de Lleu, obispado de Lleu, dedicados al comercio de textiles; ${ }^{7}$ Juan Francisco Estrabó Camon, de Bearn, ${ }^{8}$ y Bernardo Hourtane, natural de Oloron Sainte-Marie.

Estas transacciones reflejaron algunos cambios en los modelos de consumo, en la población urbana y rural, que ya se venían produciendo a lo largo del siglo XVIII. Por tanto, la economía española, especialmente la que

${ }^{1}$ Fonds Roux Frères. L. IX. Archive de la Chambre de Commerce de Marseille.

${ }^{2}$ Archivo Histórico Provincial de Murcia (en adelante AHPM). Sig. 4228, fs. 762r.-768v., escr. Atienza, Juan Mateo, t. II.

${ }^{3}$ AHPM. Sig. 2782, fs. 1r.-2v., escr. Espinosa de los Monteros, Francisco.

${ }^{4}$ AHPM. Sig. 2517, fs. 63r.-65v., escr. Blanes Jiménez de León.

${ }^{5}$ AHPM. Sig. 2535, fs. 78r.-79v., escr. Bocio y Belda, Francisco.

${ }^{6}$ AHPM. Sig. 2804, fs. 52r.-82r., escr. [no está firmada por notario].

${ }^{7}$ AHPM. Sig. 2522, fs. 98r.-99v., escr. Blanes Jiménez de León, Antonio.

${ }^{8}$ AHPM. Sig. 2841, fs. 12r.-14v., escr. Sánchez Rubio, Ignacio. 


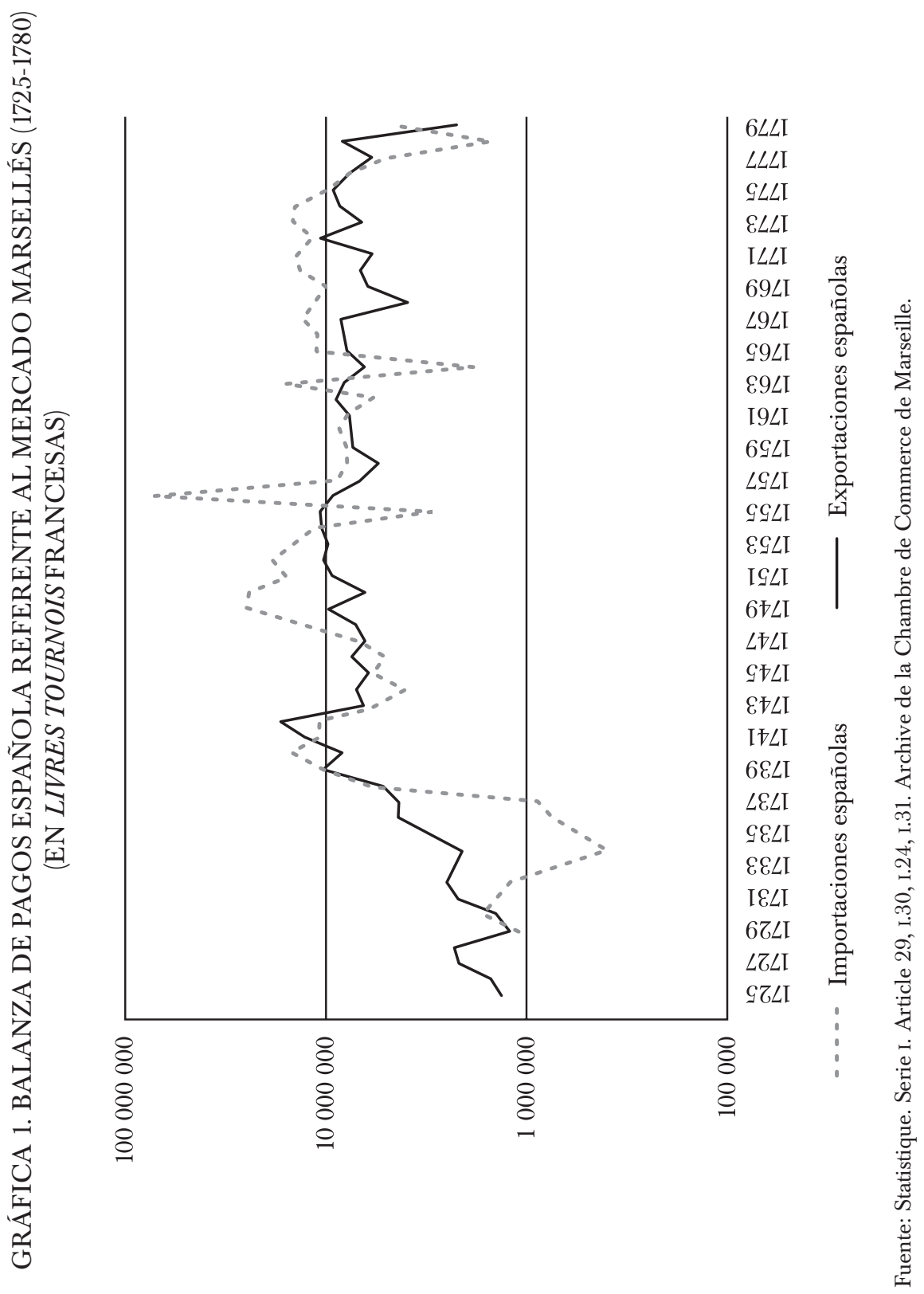


englobaba los territorios de la cuenca mediterránea al igual que los relativos a los mercados americanos, estaba más orientaba hacia el mercado, siendo este el estímulo principal que guiaba tanto a la elite local como a núcleos artesanales, grupos de pequeños emprendedores y clases medias hacia una demanda creciente de productos que arribaban de mercados internacionales (Ringrose, 1996, pp. 135-162). La demanda de una amplia gama de bienes aumentaba de forma paulatina en suelo europeo, no solamente con la finalidad de cubrir necesidades básicas, sino con el fin de lograr una mejor calidad de vida y mayor confort. España no fue una excepción en tal proceso. Los elementos principales que estimulaban la demanda eran la conexión con los citados grupos y compañías de comercio extranjeros, así como la integración con mercados globales que enlazaban las zonas mediterráneas, asiáticas y atlánticas.

El marcado valor transnacional y transcultural de los bienes que se introdujeron en territorio español hizo que existiera una mayor dependencia hacia los mercados externos para proveer este tipo bienes, debido a las características especiales relativas a los territorios donde se producían. Tanto la lana vicuña como la grana cochinilla, que analizaremos en las siguientes líneas, serían un ejemplo de este tipo de bienes transnacionales. Esto sin lugar a dudas tuvo efectos de marcados tintes socioculturales, como en la transferencia de nuevos valores, hábitos y adquisición de nuevas identidades sociales, inherentes al creciente consumo de estos productos foráneos y de comunidades extranjeras asociadas a estos artículos. El resultado final de tal proceso fue la progresiva adquisición de nuevas modas. El consumo y adquisición de estos bienes se insertan en un contexto más global. Los grupos de comerciantes, especialmente la casa Roux-Frères, podrían definirse como los principales agentes sociales y mediadores que estimularon el consumo de nuevos productos ejerciendo un papel vital tanto en la oferta como en la demanda de los mismos (Pérez, 2013).

\section{El COMERCIO DE LANA VICUÑa A TRAVÉS DE LA CASA RoUX Y SU IMPACTO EN LA ECONOMÍA ESPAÑOLA}

La balanza de pagos española continuó teniendo un saldo negativo, debido principalmente a que la exportación de materias primas seguía siendo inferior a la masiva importación de productos elaborados o semielaborados (véase gráfica 1), los cuales venían principalmente de los mercados asiáticos y atlánticos. Igualmente la progresiva entrada de materias primas procedentes de Asia minimizó de alguna forma el apogeo de las materias primas españolas en los mercados europeos. La entrada a España de lanas asiáticas procedentes de mercados del Levante es la prueba más notoria 
de tal declive (Cuenca, 2004; Davis, 1967; Pérez, 2013; Raveaux, 2008; Riello, 2010). Los agentes económicos trataron de reactivar el mercado y la producción nacional por medio de la comercialización de nuevos productos (Ringrose, 1973, pp. 285-292), como es el caso de los productos naturales y botánicos.

Igualmente, otra de las medidas que tenían como objetivo estimular la producción nacional consistía en la imitación o emulación de los bienes que venían de tierras lejanas y tratar de producirlos en suelo nacional copiando las técnicas de manufacturación con que se producían en sus países de origen. Uno de los ejemplos más ilustrativos podría ser el intento de emular la producción de las famosas indianas (Riello, 2010), que en el caso español tenían sus núcleos de producción principalmente en territorio catalán. El reglamento de libre comercio de 1778 no conllevó una reducción de la entrada de bienes extranjeros y tampoco supuso un impulso para estimular las industrias nacionales. En suelo nacional no se frenó la continua entrada de productos exóticos. Esto debido a que tanto el sector artesanal, representado por las obsoletas corporaciones gremiales, como el agrícola necesitaron sustanciales mejoras con el fin de encontrar bienes sustitutivos a los productos que se introducían procedentes de mercados internacionales (Martín, 2008, pp. 61-78; Stein y Stein, 2003, p. 70).

Durante el reinado de los primeros Borbones, podemos encontrar en España algunas medidas o decretos con la finalidad de prohibir la introducción de bienes extranjeros en territorio español, aunque el resultado final no fue el que se hubiese deseado. La progresiva integración de los mercados españoles y europeos en un contexto más global hizo prácticamente imposible que existiese alguna eficaz medida emanada de las autoridades gubernamentales para frenar la constante entrada de productos foráneos. Los decretos mercantilistas fueron en todo momento estériles para poner freno al aumento de las nuevas necesidades de los consumidores, los cuales gestaban en última estancia nuevas formas de un consumo global que interconectaba mercados de Oriente y Occidente.

A pesar de todos esos intentos reformistas que pretendían fomentar las industrias nacionales, la balanza de pagos española permaneció en todo momento negativa. Uno de los principales recursos económicos que inyectaban más caudales a la monarquía española era la exportación de materias primas (Fabrégas, 2005, pp. 285-310; Martínez, 1992, pp. 58-72; Oliva y Martínez, 2005, pp. 11-18). La exportación de lana constituye uno de los casos más paradigmáticos. Los principales centros de producción de lana en suelo peninsular se encontraban localizados en el norte de Castilla, siendo Segovia uno de los núcleos productores desde donde se exportaba lana, al igual que el sur de Castilla, donde la zona de Huéscar, en el reino de Granada, y toda la comarca limítrofe con la zona de Murcia y Almería, 
que recorría toda la sierra de la Sagra, se caracterizaba por la alta producción lanera. Lana cruda de gran calidad era distribuida a través de las rutas comerciales septentrionales castellanas que conectaban Segovia con los puertos de Santander, Barcelona y Valencia para su posterior exportación a los principales centros de producción textil europeos. La lana lavada y semilavada procedente de Huéscar, donde se encontraban los principales lavaderos de lana, era conducida a los ejes portuarios de Cartagena y Alicante para ser exportada a los mercados europeos (Fernández, 1996, pp. 343-362; García, 1989, pp. 629-638).

Hemos de señalar igualmente la exportación de la lana de vicuña procedente de las colonias españolas de América, principalmente de Perú, a Francia. Los registros comerciales que aquí señalamos son los referentes a las fuentes estadísticas de la Chambre de Commerce de Marseille, a través de las transacciones de la casa Roux-Frères, que muestra una alta comercialización de estas fibras textiles procedentes de Perú. Evidentemente el comercio de lana de vicuña peruana, por medio de grupos y compañías de comercio marsellés, suponía una notoria participación francesa en enclaves comerciales coloniales que eran monopolio de la monarquía española. Este hecho demuestra que los proyectos mercantilistas, emanados principalmente de los gobernantes ilustrados castellanos, cuya finalidad era controlar las rutas comerciales que conectaban con los mares del Sur y evitar el contrabando e intrusión extranjera, fueron más que estériles. El comercio de la lana de vicuña peruana por parte de los comerciantes y negociantes marselleses representaría un claro ejemplo de ello.

La posibilidad de que territorios del imperio español, como Nueva España para el caso de la grana cochinilla y el virreinato de Perú para la comercialización de lana de vicuña se convirtiesen en un eje comercial para la extracción de tales materias primas y posterior manufacturación de textiles en suelo francés, explica la constante injerencia de la actividad mercantil de negociantes marselleses en las colonias españolas de América (Christelow, 1941). Las colonias francesas en la región norte del continente americano eran demasiado jóvenes para ejercer tal función como proveedoras de materias primas relativas al ramo textil, por lo que hubo una clara inclinación hacia las colonias españolas de América que claramente podrían ejercer tal función. Decretos y leyes españolas, cuyo fin era poner freno al comercio extranjero en territorios del imperio, no evitaron la constante participación francesa. Estos decretos tuvieron un efecto opuesto, ya que fomentaron el comercio no reglado o contrabando francés y británico en las colonias españolas (Brown, 1928).

Destaca en este sentido el proyecto de un nuevo sistema mercantil ideado en 1711 por el virrey de Nueva España, el duque de Linares, con el fin de abrir el comercio entre Nueva España y Perú por el Mar del Sur, 
sustituyendo al eje España-Portobello-El Callao, y eliminar así el comercio de contrabando francés que iba de Manila a Lima para recorrer todo el Mar del Sur doblando el cabo de Hornos hasta España (Bonialian, 2012, pp. 93-119; Fisher, 1985a, 1985b). Este proyecto no se llevó a cabo, pero ilustra los intentos de la monarquía española por frenar el contrabando francés en los circuitos comerciales exclusivos de dominio español.

Las cifras del cuadro 1, comparando la exportación a Marsella de lana segoviana y lana peruana de vicuña a través de la mediación y comercialización marsellesa, presenta datos desiguales, siendo muy superior la segoviana, aunque el volumen de lana peruana es significativo para mostrar la participación francesa, mediante el contrabando o comercio ilegal o no reglado, en un producto que en primera instancia era único y exclusivo del monopolio español en el comercio del Mar del Sur. A pesar de que el comercio francés estaba permitido con los puertos americanos mediante la concesión de licencias especiales, estableciendo que los retornos debían estar constituidos de modo mayoritario por frutos del país, está demostrado por especialistas como De Sousa (2010) la existencia de comercio no reglado por comerciantes franceses en el Pacífico. En este sentido, la gráfica 6 muestra tal participación francesa en el comercio con las colonias españolas de América, en donde se observa cómo todo el gran volumen de mercancías tenía a Marsella como destino final, en lugar de revertir en beneficio español. Esto tuvo efectos negativos en la economía española, ya que mercancías que se producían en territorios de dominio español se dispersaban por territorios europeos.

La lana elaborada de Segovia, así como la lana lavada procedente de los lavaderos de Huéscar en el Reino de Granada, tenía una alta demanda en los centros de producción textil del sur de Francia, hecho que se corrobora a través de los altos volúmenes de exportación desde los puertos mediterráneos de España hacia Marsella. Su precio era más o menos constante durante la primera mitad del siglo XVIII (véase gráfica 2). En el periodo posterior podemos apreciar algunas fluctuaciones en el precio de la lana española, factor que puede explicarse por el contexto de una mayor entrada en suelo europeo de lanas y algodones procedentes de los mercados británicos, asiáticos y americanos, así como los que se introducían a través de la caravana de Levante. La ruta levantina integraba los mercados de Oriente Próximo, en la cuenca más oriental del Mediterráneo, con los europeos. ${ }^{9}$ La lana peruana era altamente demandada por los

\footnotetext{
${ }^{9}$ Véanse los trabajos de Pat Hudson (2008) referentes al impacto de la lana británica en los mercados europeos. Beverly Lemire (2008) ha estudiado en profundidad el impacto de los textiles, lanas, algodones y cotonías asiáticos en el proceso de sustitución de algodones y lanas asiáticas por los europeos con el fin de satisfacer la demanda nacional sin tener que abastecerse de textiles asiáticos.
} 


\section{CUADRO 1. VOLUMEN TOTAL DE EXPORTACIONES DE LANA DESDE LOS PUERTOS MEDITERRÁNEOS \\ DE ESPAÑA Y PERÚ HACIA MARSELLA (1720-1780)}

\begin{tabular}{lc}
\hline & Totales \\
& (en libras francesas, 1 libra $=0.4895$ gramos) \\
Lana elaborada de Segovia & 6488112 \\
Lana elaborada de vicuña (Perú) & 561571 \\
Lana lavada & 3966885 \\
Lana semilavada & 62753 \\
\hline
\end{tabular}

Fuente: Statistique. Serie I. Article 29, I.30, I.24, I.31. Archive de la Chambre de Commerce de Marseille.

centros textiles europeos debido a su alta calidad y mayor tamaño y grosor respecto a la lana producida en centros castellanos (Salas, 1998). Aunque su comercialización era menor en comparación a la castellana, se puede observar una tendencia al alza a lo largo del siglo XVIII en el volumen de lana de vicuña que llegaba a Europa desde Perú (véase gráfica 3). Ropas hechas con lana peruana eran altamente de lujo, siendo los grupos sociales más adinerados los que podían permitirse la adquisición de vestidos hechos con fibras de vicuña. La demanda de este tipo de fibras corroboraría que la creciente producción de lana de vicuña peruana fomentó de alguna forma el comercio de materias primas y textiles semielaborados con las colonias españolas de América (García, 1980; Malamud, 1981, p. 46, y 1983; Walker, 1979).

Durante el siglo XVIII la vicuña estaba en peligro de extinción, prácticamente al escasear la producción de lana de este camélido empezó a sustituirse posteriormente por la de otra variedad como la llama o guanaco. En 1737 un aventurero inglés (Ulloa, 1772), que se encontraba visitando los telares en los talleres donde se confeccionaban textiles con la preciosa y valiosa lana de vicuña, desarrolló un monopolio sobre la producción y confección de textiles con este tipo de lana. En concreto se especializó en la producción de sombreros, posteriormente vendió la patente a un emprendedor mestizo llamado Felipe de Vara. Las vicuñas fueron casi extinguidas en tal proceso, por lo que los propietarios de estos talleres ocultaban en lugares apropiados la lana de vicuña con el fin de evitar que los pastores adulterasen la materia prima con lana de llama, que era la que más abundaba (Ulloa, 1772). Como presentamos en los datos y estadísticas sobre la comercialización de lana de vicuña por negociantes marselleses, 


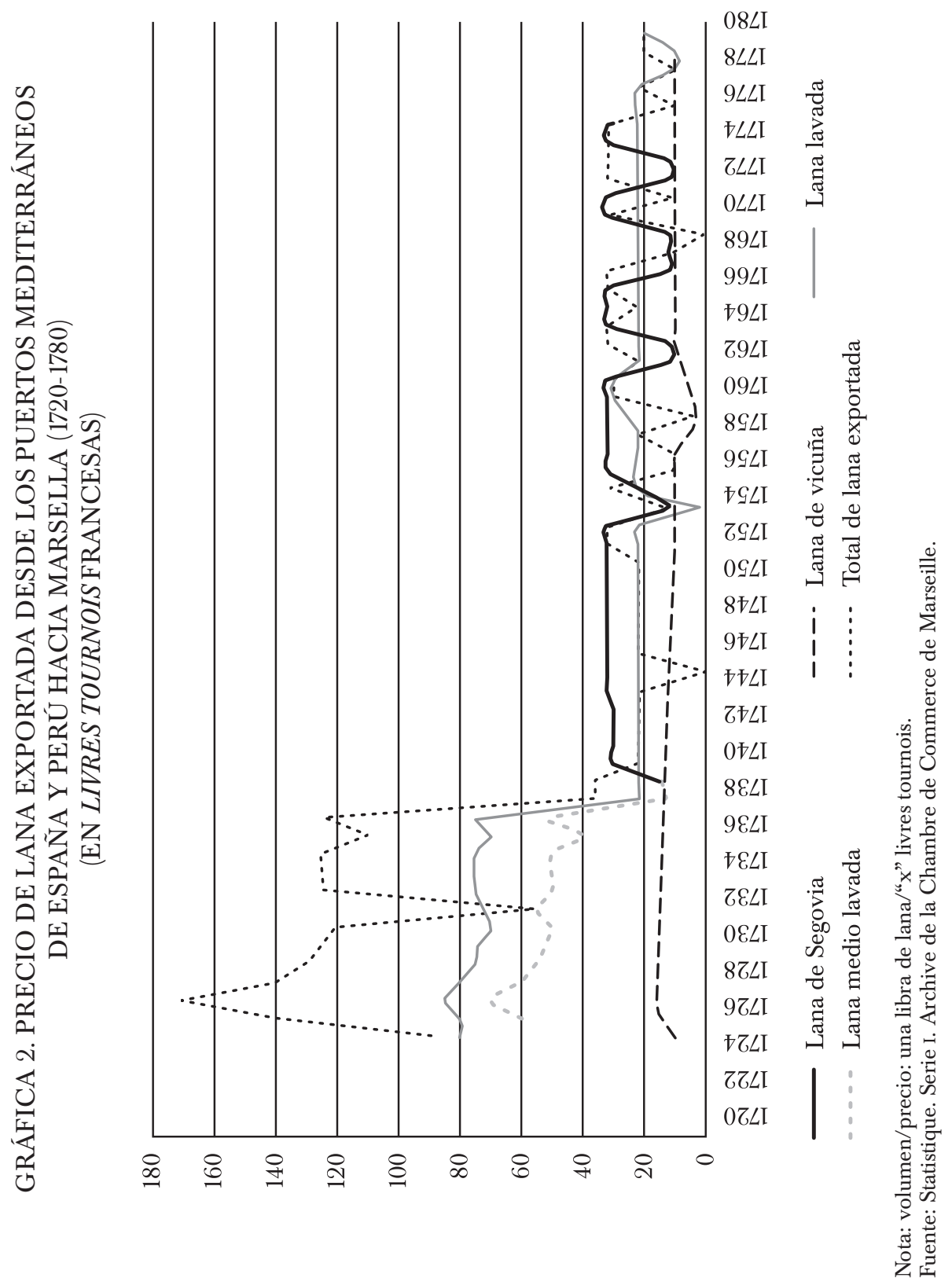



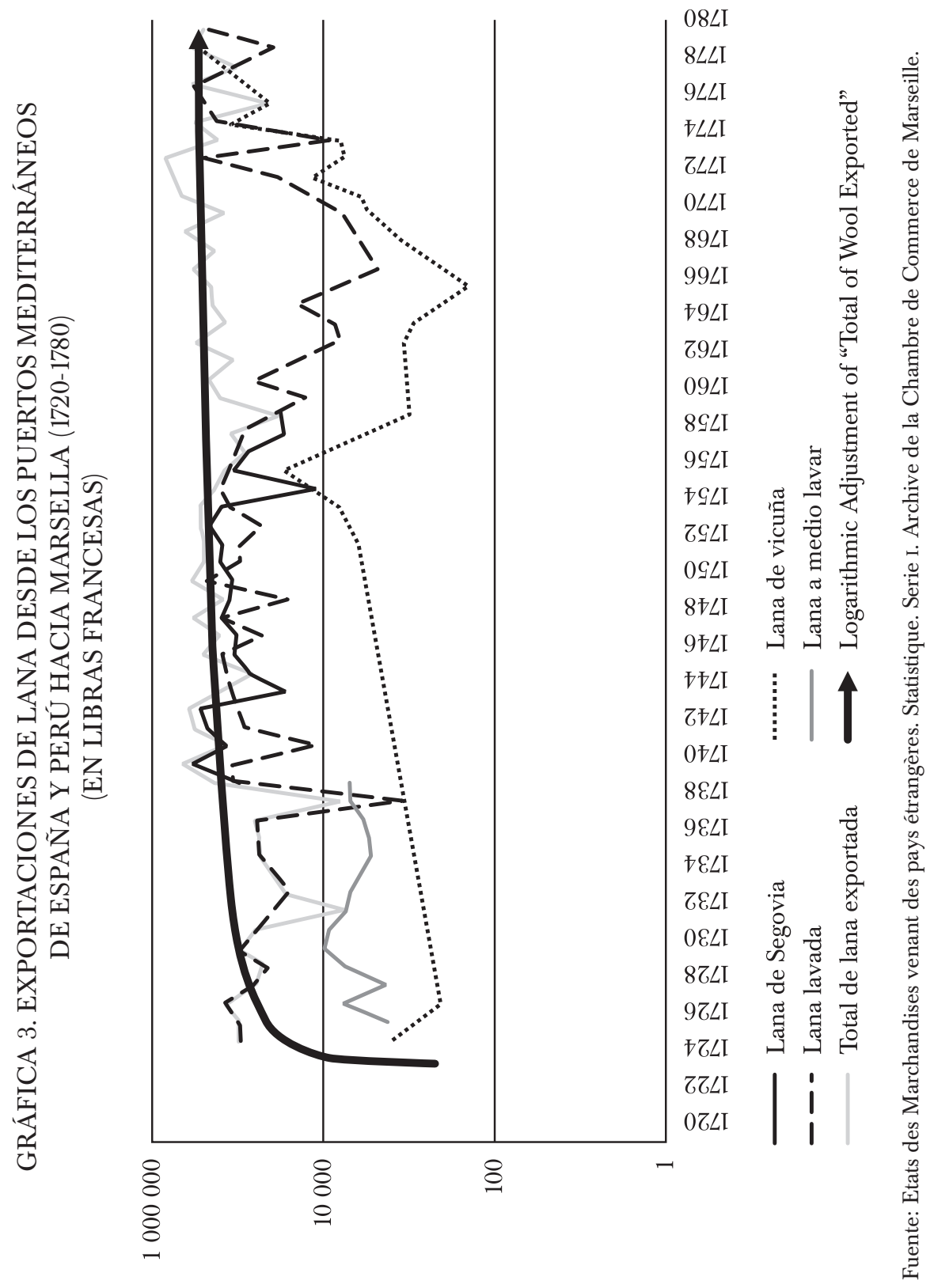
esta lana, tal y como nos describe la fuente, es de vicuña y no de llama o guanaco (véanse cuadro 1, gráficas 2 y 3). El trabajo de producción era ciertamente monótono, tedioso y muy fatigoso para la población nativa que trabajaba en la confección de textiles con lana de vicuña (Wiedner, 1960).

La procedencia de la vicuña es el altiplano andino, noroeste de Argentina, oeste de Bolivia, noroeste de Chile, sectores de los Andes de Ecuador, y alturas andinas de Perú, donde la población de vicuña es más numerosa (Escobari, 2014). Según nos relatan las fuentes de la Chambre de Commerce de Marseille, de esta última zona es de donde procedía la lana de vicuña que se comercializaba a través de los negociantes marselleses, en concreto los Roux. La principal característica de la vicuña es que produce pequeñas cantidades de lana de una finísima y gran calidad, siendo muy costosa, por ello confeccionar una amplia gama de prendas textiles requería la lana de muchas vicuñas (Escandel, 1997). El tipo de la lana es suave y muy caliente (Koford, 1957). Estas características especiales hicieron que las prendas hechas con lana de vicuña fueran vistas como un producto de consumo ostentoso, ya que en primera instancia era usado por los incas, y estaba prohibido portar textiles de vicuña por aquellos que no perteneciesen a la realeza. Posteriormente en Europa las prendas textiles hechas con lana de vicuña se destinaron a miembros de la alta realeza, la nobleza y el alto clero.

El comercio que integraba los mercados más occidentales del Mediterráneo con territorios de ultramar, especialmente con el Atlántico, consolidaba de esta forma su solidez y dinamismo a través de la entrada de materias primas para la elaboración de manufacturas textiles, así como productos elaborados y semielaborados. La progresiva afluencia de estos productos en suelo peninsular hizo que la balanza de pagos española, en lo referente al monto global relativo al comercio internacional, permaneciese negativa. Los productos que entraban en territorio metropolitano eran de origen agrícola y animal, procedentes sobre todo del área caribeña, Nueva España, Nueva Galicia, Nueva Granada y virreinato de Perú. También debemos señalar que tras la desmembración del virreinato de Perú en el siglo XVIII, en diversos momentos la grana y la lana de vicuña, al igual que la ovina, llegaron también de los virreinatos de Nueva Granada y del Río de la Plata. Aunque en este artículo nos centramos en la grana procedente de Nueva España y en la lana de vicuña de Perú, que es la que mayormente comerciaban los negociantes marselleses como los Roux; los registros de la Chambre de Commerce de Marseille relativos a la compañía Roux así lo demuestran. De hecho, eran materias primas y bienes que en buena parte, como en el caso que presentamos aquí a través del comercio francés, eran reexportados desde Marsella a otros territorios europeos, no solamente España (Beeson, 1964; Floyd, 1965; Lee, 1948; Smith, 1959). Por un lado, 
la participación francesa en las actividades mercantiles de exclusividad española en las colonias americanas y, por el otro, el desvío comercial de estos productos fuera de los territorios de dominio de la monarquía española, produjeron deslocalización tanto de la plata americana como de los géneros exclusivos de la monarquía, teniendo efectos altamente negativos para la economía española (Boxer, 1970, pp. 457-475; Chaudhuri, 1997, pp. 61-79; Flynn y Giráldez, 2002, pp. 391-427; Marichal, 2006a, pp. 25-52).

De esta forma, las casas y compañías de comercio, especialmente las redes de comerciantes marselleses como los Roux, reexportaban cochinilla, índigo y lana de vicuña a los principales centros de producción textil europeos. La casa Roux era la que tenía mayor volumen de negocios hacia estos productos. Esto explica el enorme volumen de los registros de la Chambre de Commerce de Marseille, que atestiguan las transacciones comerciales de cochinilla, índigo y lana de vicuña por parte de negociantes y mercaderes franceses. Los negociantes marselleses adquirieron de facto estos productos que, como dijimos, eran de exclusividad española, distribuyendo posteriormente las materias primas textiles y productos tintóreos a centros de producción textil localizados en territorio francés, como los del Languedoc y Provenza, o italiano, destacando Turín, para manufacturar ropas y bienes textiles que estaban a la moda europea.

\section{El COMERCIO DE GRANA COCHINILla A TRAVÉS DE LA CASA ROUX Y SU IMPACTO EN LA ECONOMÍA ESPAÑOLA}

En la propia fuente relativa a los registros de la Chambre de Commerce de Marseille aparece una lista detallada estableciendo una clasificación tipológica de la cochinilla que se exportaba de América a Francia: silvestre, fine, mestegue, en grabeau y cochinilla sin denominación, la cual deducimos que sería cochinilla madura o grana (véase cuadro 2). La grana cochinilla, o Dactylopius coccus, es un minúsculo insecto perteneciente a la familia de los hemípteros. Tal insecto se alimentaba de una variedad de nopales, conocida como Opuntia, lo que produce en sus entrañas un ácido carmíneo cuya finalidad y aplicación era para teñir fibras vegetales y animales. Dos tipos de cochinilla, como la grana y la silvestre, las cuales aparecen igualmente dentro de la tipología de grana comercializada por los negociantes de Marsella que presentamos en este estudio, son las más citadas por las fuentes históricas. La procedencia del cultivo y cría de grana es la zona de los pueblos indios del centro y sur de México, siendo tal cultivo la principal actividad económica de esta zona. Las provincias de Oaxaca, Puebla y Tlaxcala se caracterizaron por la domesticación y crianza de la grana fina, mientras que la silvestre se extendía en territorios pertenecientes a las 
provincias de Chiapas, Guerrero, Michoacán, Jalisco y Yucatán (Arrioja, 2013; Ávila, 2001; Donkin, 1977; Ortiz, 2010). Las principales zonas productoras se situarían en Oaxaca, donde destacan los Valles Centrales, la Mixteca, la Cañada y el istmo de Tehuantepec. También se produce en territorios de América del Sur, aunque aquí nos centramos en México. En las fuentes de la primera mitad del siglo XVI las zonas citadas son señaladas como vitales centros productores y posteriormente, a finales del siglo XVI e inicios del XVII, emergieron las zonas de Puebla y Tlaxcala. Para precisar sobre el cultivo y técnicas de producción de la grana cochinilla y observar el proceso desde la cría de insectos hasta la obtención del tinte carmín, la mayor parte de trabajos remiten a José Antonio de Alzate y Ramírez, quien hacia 1777 elaboró una detallada descripción sobre las técnicas de cultivo de la grana, siembra de nopaleras y extracción del preciado tinte:

plantar los nopales haciendo agujeros en línea recta de una cuarta de hondo y una tercia de ancho, y cortando de las plantas viejas las hojas grandes y verdes, introducir tres en cada agujero, hasta la mitad, sin arrimarlas ni cubrirlas de tierra, y luego a los pocos días prenden y echan raíz por la humedad de la tierra..., estas siembras se hacen por los meses de mayo y junio, y lo mismo hacen luego que las aguas se quitan por noviembre y diciembre... y seguir limpiándolas al menos dos veces al año de la hierba que produce la tierra, y a los tres años según el terreno están en aptitud de recibir la semilla de la grana... (Alzate, 2005, pp. 160-163).

La grana era exportada a Europa en grandes volúmenes debido a las técnicas de preparación y elaboración, las cuales eran muy específicas y difíciles de emular en los centros de producción textiles europeos y españoles. Las técnicas en la preparación de la grana que ejecutaban los indios nativos eran más precisas en todo el proceso de elaboración y cultivo de la cochinilla, el cual resultaba bastante tedioso para una mano de obra no cualificada como era la española. Los principales centros de producción de este tinte se localizaban en las áreas de Nueva España, Nueva Galicia y Nueva Granada (Baskes, 2000; Dalhgren, 1990).

Durante el periodo de conquista la comercialización de este tinte de origen animal fue desdeñada por los colonos españoles, pero hacia finales del siglo XVI e inicios del XVII comenzaron a apreciar la importancia de este producto, el cual ayudó a fabricar ropas y vestidos con una amplia gama y vistosidad cromática (véanse gráficas $7,8,9,10,11$ y 12), confeccionando prendas que estaban a la moda (Alzate, 2005; Sánchez y Suárez, 2006, pp. 473-490). ${ }^{10}$ Aunque en sus inicios este producto fue rechazado

${ }^{10}$ Catherine Larrère afirma que a finales del siglo XVIII algunas regiones de India comenzaron a cultivar la grana en enormes cantidades. Según esta autora, este colorante comenzó a 


\section{CUADRO 2. EXPORTACIÓN DE COCHINILLA \\ DE LA AMÉRICA ESPAÑOLA A MARSELLA (1720-1780)}

\begin{tabular}{lcc}
\hline Tipo de cochinilla & $\begin{array}{c}\text { Volumen total } \\
\text { (en libras) }\end{array}$ & $\begin{array}{c}\text { Valor total } \\
\text { (en livres tournois francesas) }\end{array}$ \\
Cochinilla & 2451550 & 66981900 \\
Cochinilla en grabeau & 27978 & 276995 \\
Cochinilla fine & 794546 & 13897779 \\
Cochinilla mestegue & 554586 & 10188815 \\
Cochinilla silvestre & 134381 & 832002 \\
\hline
\end{tabular}

Fuente: Statistique. Serie I. Article 29, I.30, I.24, I. Archive de la Chambre de Commerce de Marseille.

por los colonos y las autoridades peninsulares, viajeros y misioneros, como es el caso del fraile franciscano Motolinía, se dieron cuenta de su gran importancia. Antes del año de 1550, el fraile franciscano Motolinía escribió el siguiente pasaje revelando el alto valor de la cochinilla: "en estas tunas, las cuales son de color rojo, la grana nace, en esta lengua es llamada mocheztli [...] Es una cosa de gran valor, ya que es de color rojo brillante. Entre los españoles se llama carmesî" (Benavente, 1941, p. 197; Lee, 1948, pp. 449-473). El color brillante que la grana otorga a las prendas de vestir y a los textiles del hogar contribuyó a que el comercio de la cochinilla adquiriese una mayor importancia no sólo entre los comerciantes españoles, sino también entre el resto de comerciantes de Europa. La introducción de este producto fue muy bien recibida por el gremio de teñidores debido a la creciente demanda en la sociedad europea ${ }^{11}$ de ropas y prendas teñidas con grana, ya que la tonalidad escarlata llegó a estar estrechamente asociada con la riqueza y con la realeza (Born, 1938, p. 226; Friis, 1927). La llegada de la grana supuso una "democratización" del rojo, antes obtenido con la púrpura, demasiado costosa. Un proceso similar ocurrió con el añil. Tal proceso creó nuevos usos y costumbres de las prendas de vestir que ha sido muy bien estudiado por Daniel Roche (1989). Felipe II creó el cargo de juez de grana, el cual llegó a ser altamente lucrativo, ya que la producción de cochinilla creció exponencialmente. Sin embargo, en el siglo XVIII es

comercializarse en las zonas del Lejano Oriente, así como los mercados armenios, turcos y persas (Larrère, 1992, pp. 95-140).

${ }^{11}$ Houghton, en su análisis del consumo de colorantes en Inglaterra, coloca el índigo o añil en primera posición seguido del granza, cochinilla, orchilla y musgo, cúrcuma, madera de Campeche y "goma laca" (Houghton, 1887, p. 84). 
cuando se produce un mayor flujo de comercialización de cochinilla desde los centros productores de la América hispana a Europa, especialmente en el periodo comprendido desde 1758 hasta 1783 (Marichal, 2006b, p. 82).

Los datos aportados por John Fisher en su trabajo sobre el comercio con las colonias españolas de América (Fisher, 1985a, pp. 35-78), así como los datos que nosotros mismos mostramos en el presente trabajo en referencia a la integración de mercados coloniales del Nuevo Mundo con el territorio más occidental del Mediterráneo, es la prueba más fehaciente que demuestra claramente la elevada comercialización de este colorante en Europa a lo largo de la centuria dieciochesca (véase cuadro 2). Sin embargo, a diferencia de las cifras de Fisher, que muestran exclusivamente la comercialización de cochinilla en los puertos españoles una vez promulgado el decreto de libre comercio en 1778, nuestros datos muestran la creciente participación francesa durante todo el siglo XVIII en el comercio de bienes coloniales españoles, como la cochinilla o la lana de vicuña, creándose rutas alternativas a las españolas que iban desde Veracruz a Cádiz, a través de las redes de negociantes marselleses para la entrada de estos productos en Europa. Se crea de esta forma un comercio directo entre Marsella y los puertos americanos. Las rutas alternativas serían, como señalábamos anteriormente, las que conectaban los mares del Sur e integraba el comercio Pacífico con el Atlántico. El decreto de libre comercio no frenó el comercio no reglado de estos productos (Sousa, 2010), sino que estimuló y fomentó la creación de redes comerciales transnacionales en donde participaban tanto comerciantes nativos de Oaxaca (para el caso de la cochinilla) y andinos (para la lana de vicuña), como mestizos, españoles y franceses. La formación de tales redes tenía como fin la superación de los obstáculos inherentes a la producción, comercialización y transporte de cochinilla.

En el caso concreto de la cochinilla, esta era muy pesada. Normalmente se transportaba a España en cargas de ocho arrobas (una arroba equivalía a 25 libras españolas o 25 libras inglesas), y en una carga se transportaban 225 libras (Hamnett, 1971). Debido al auge de la industria textil europea, desde el siglo XVI en adelante, coincidiendo en especial con los textiles fabricados con algodón tanto europeo como el proveniente de los mercados asiáticos y atlántico (lana de vicuña), la comercialización y uso de este tinte proveniente del Nuevo Mundo vio su época de esplendor en la segunda mitad del siglo XVI y continuó un importante crecimiento secular durante los siglos XVII y XVIII. Esta última centuria coincidió sobre todo con el auge de las exportaciones de lanas americanas, como la lana de vicuña. Debido a tal apogeo, el comercio de la grana cochinilla llegó a ser muy lucrativo, de ahí que se articulasen importantes redes mercantiles (Valle, 1992) conectando las principales zonas productoras de este tinte, 
como Tlaxcala, Puebla, los pueblos de Otumba o Cempoala, Nueva Galicia o Oaxaca, con los principales enclaves portuarios europeos como Cádiz, Cartagena o Marsella (Valle, 2011). El enclave que conectaba ambos lados del Atlántico en los circuitos comerciales de cochinilla era el puerto de Veracruz.

Los pequeños comerciantes y suboficiales situados alrededor de las principales zonas productoras de grana cochinilla eran los agentes mediadores en la distribución del tinte desde los mercados locales de Oaxaca que conectaban con mercados europeos. De este modo, se ejercía una función de enlace entre agentes productores y negociantes, integrando los mercados internacionales en una red comercial que se comenzaba a tejer a escala local, adquiriendo a la postre una morfología global. Desde Puebla la grana era transportada en mulas hasta zonas portuarias, Veracruz era el puerto desde donde se distribuía a los distintos enclaves europeos. Esta red unía a las familias productoras de grana cochinilla, básicamente familias de origen indígena, con los funcionarios coloniales (alcalde mayor, juez de grana, subdelegados y tenientes) encargados de la supervisión en la producción y distribución comercial del tinte, desde que salía de Oaxaca hacia Veracruz; de ahí las redes de comerciantes de Cádiz y Sevilla lo redistribuían hacia otras zonas europeas (Sánchez y Suárez, 2006). Sin embargo, a la luz de los datos que aportamos (véanse cuadro 2 y gráfica 4) sobre el gran volumen de cochinilla que las redes de comerciantes franceses introdujeron en Europa, vemos cómo especialmente los negociantes marselleses contribuyeron a que Marsella adquiriese el papel de nuevo eje redistribuidor de cochinilla. Este hecho deja entrever claramente la creciente participación francesa y la función del puerto de Marsella, a través del comercio no reglado o contrabando, en una actividad comercial que en primera instancia era de monopolio y exclusividad española. Sirvan como ejemplo las redes mercantiles que negociantes marselleses como los Roux, Gilly o Aillaud tejieron en torno al próspero negocio de la grana cochinilla. ${ }^{12}$ Igualmente, este hecho señala que el desplazamiento del mercado y exportaciones de territorio novohispano hacia Marsella se produjo mucho antes del primer cuarto del siglo XIX (Sánchez y Suárez, 2006, p. 481), momento señalado como de crisis del comercio de cochinilla de Nueva España.

Este producto estimuló en la sociedad europea la demanda de una gran variedad de vestidos y prendas teñidos con el brillante color escarlata o carmesí (véanse gráficas 7, 8, 9, 10, 11 y 12). El volumen de exportaciones de distintos tipos de cochinilla, comercializada desde las colonias ame-

${ }^{12}$ Fonds Roux Fréres. Manifestes des navires entrés á Marseille (1757-1771). L. IX, 102. Archive de la Chambre de Commerce de Marseille. 
ricanas hasta los centros de producción textil de Europa, principalmente franceses, alcanzó la no despreciable cifra de casi 4000000 de libras -18 livres tournois por libra de cochinilla $-{ }^{13}$ desde 1725 hasta 1780 .

El precio medio de la cochinilla por unidad se situaría alrededor de entre 15 y 20 livres tournois francesas (41 y 55 pesos de a ocho) (véase gráfica 5), existiendo algunos periodos de fluctuación a inicios de la década de los treinta y cincuenta del siglo XVIII que se podrían explicar por la interrupción del comercio francés en el año 1729 debido a la plaga de Marsella y a los conflictos coloniales provocados por la guerra de los Siete Años a mediados del siglo XVIII. Por lo tanto, la importación en Marsella tanto de cochinilla como lana de vicuña aumentó hasta el último tercio del siglo XVIII, periodo en el cual su comercialización empezó a descender, especialmente en el caso de la lana de vicuña, en comparación con otros tipos de lana, y al mismo tiempo sus precios fueron disminuyendo a lo largo del mismo siglo (véanse gráficas 2 y 5). Otros tipos de lana, así como de tintes, mantuvieron precios poco competitivos, lo que permitió que la grana cochinilla y la lana de vicuña mantuviesen una creciente demanda en Europa debido a las características de la fibra y al color brillante que el tinte confería a la prendas textiles (véanse gráficas 3 y 4 ).

Así como el precio de la cochinilla se mantuvo constante en mercados del Mediterráneo occidental, no pasando la libra de cochinilla de entre 15 y 20 livres tournois, en mercados nórdicos de Europa sucedió más o menos lo mismo. Alexander Engel estudió el mercado de Hamburgo, en donde el precio de la libra de cochinilla se mantendría constante, alrededor de 44 reichsthaler (368 pesos de a ocho) (Engel, 2007, p. 3), ya que dicho mercado era dominado por propietarios de plantaciones, comerciantes o tintoreros, así como por las grandes compañías que lo monopolizaban, como la East India Company (EIC) o la Vereenigde Oostindische Compagnie (Voc) (Chaudhury y Morineau, 1999). Al igual que en Marsella, en Hamburgo, Londres o Amsterdam los precios corrientes eran publicados en listas correspondientes a su precio de venta al por mayor, y tales precios mantendrían una tendencia secular constante (Gerhard y Kaufhold, 2001; McCusker y Gravesteijn, 1991). Esto no se debe a la falta de atención o de dinamismo por parte de los agentes comerciales o de los negociadores de la cochinilla en mercados europeos, sino a que la estructura de estos mercados permaneció prácticamente estable al menos durante dos generaciones.

${ }^{13}$ Statistique des merchandises venant des pays étrangeres (1725-1745). Reference I. 29. Archive de la Chambre de Commerce de Marseille. 


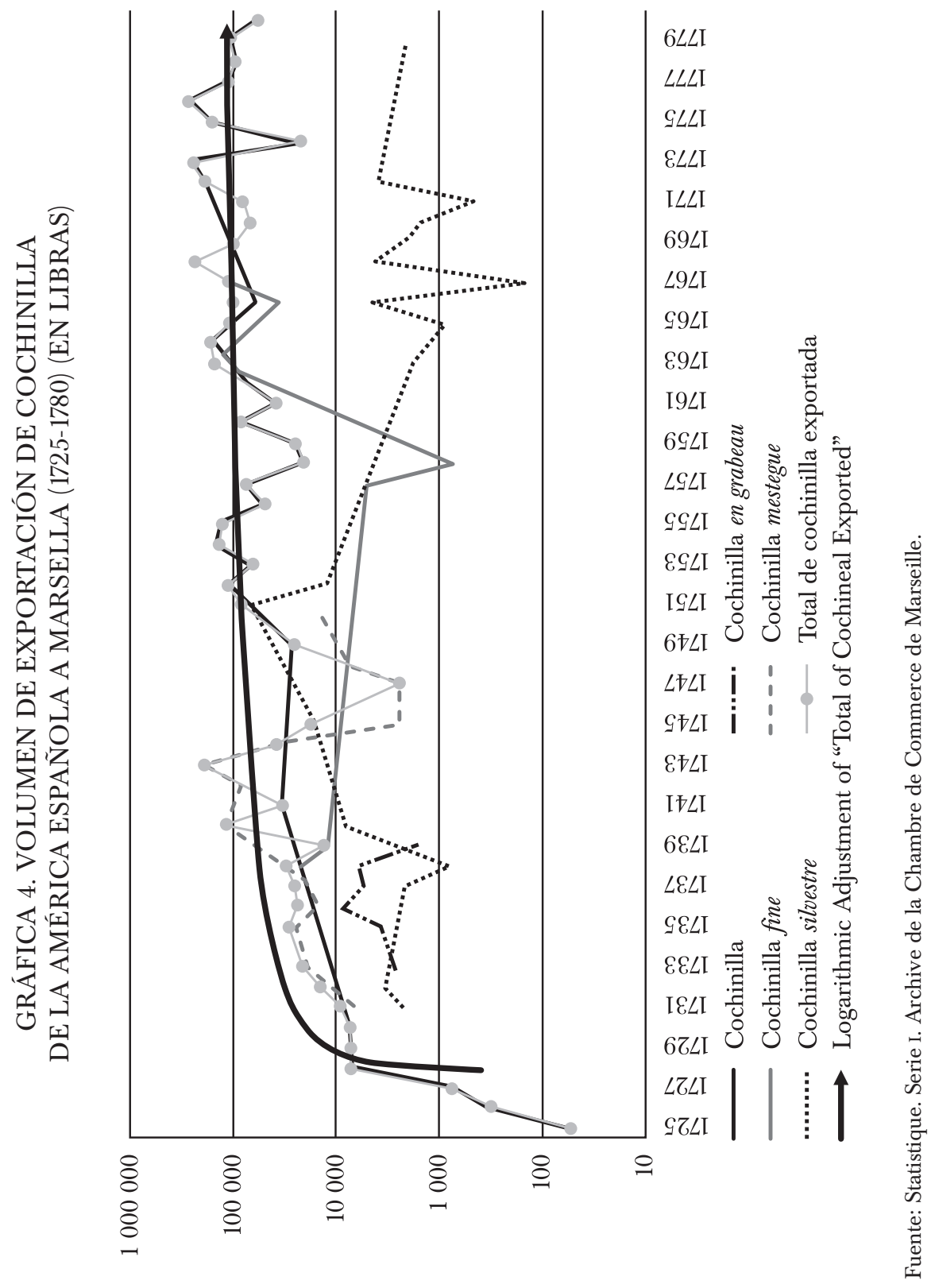




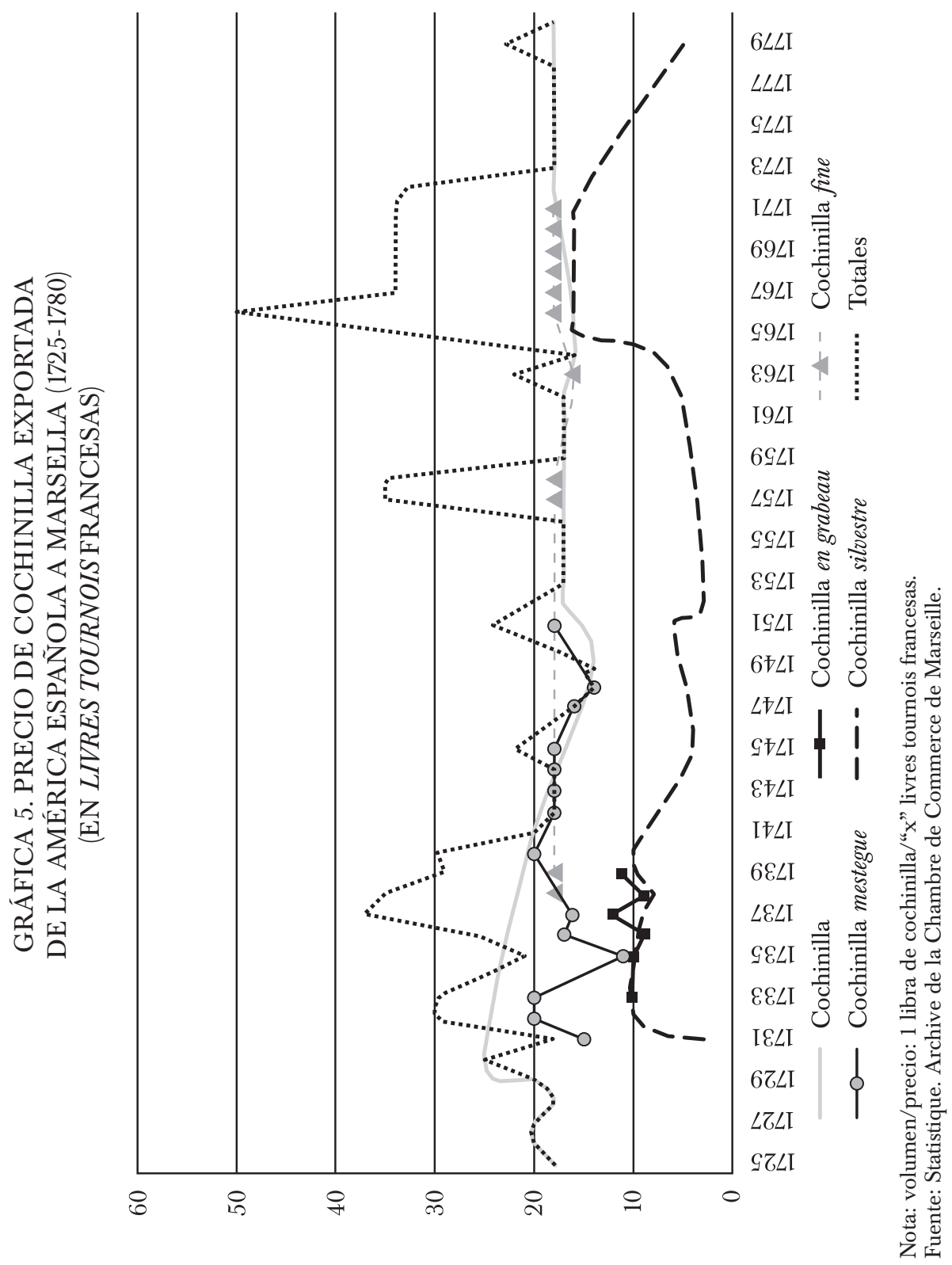




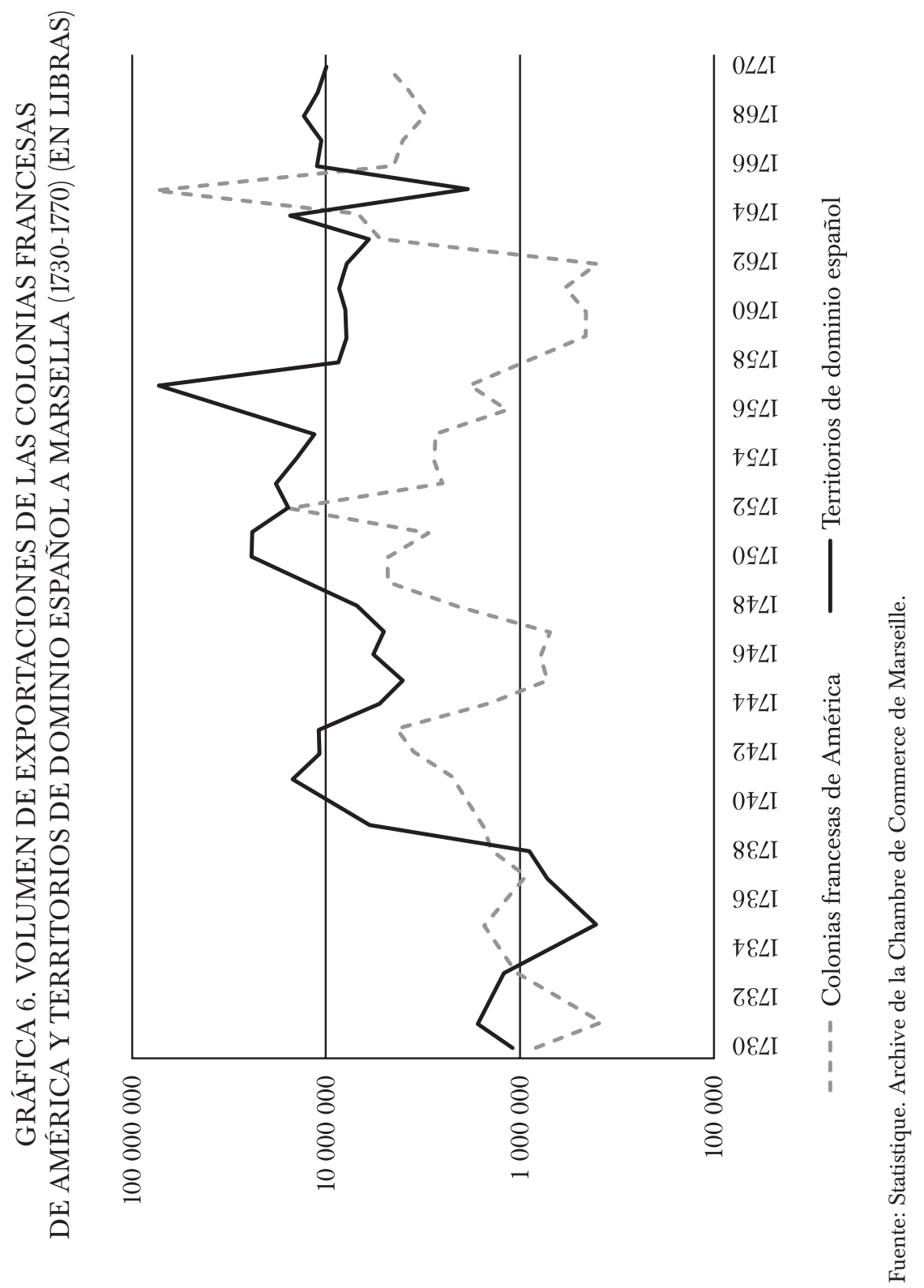




\section{IMPACTO DE LA LANA VICUÑA Y DE LA GRANA EN EL CONSUMO}

\section{DE PRENDAS DE VESTIR Y MODAS}

El comercio de tintes americanos complementaba el de lanas, secular desde el siglo XVI, y en el que la grana era el más caro. Para ver tal complementariedad hemos considerado pertinente mostrar un cuadro de la evolución del consumo de lana y de prendas de vestir cromadas con tintes procedentes de las colonias americanas, haciendo una comparación de tal evolución en dos periodos: el que comprende los años de 1730 hasta 1769 , y el que va desde 1770 hasta 1808 , año de gran inestabilidad debido al inicio de las guerras napoleónicas (véanse gráficas 7, 8, 9, 10, 11 y 12). La variedad cromática en las prendas de vestir y en las indumentarias se ve reflejada en los inventarios post mórtem y en las dotes que hemos analizado en el Archivo Histórico Provincial de Murcia para ver la evolución en el consumo de estos bienes observando el caso concreto del sureste de la corona de Castilla durante el siglo XVIII. En estos datos hemos incluido el consumo de estos productos relativo a áreas urbanas y rurales correspondientes a los enclaves de Murcia y Cartagena. El enclave portuario de la zona de Cartagena fue importante en la introducción y comercialización de estos productos en la zona castellana debido al auge de Cartagena durante el siglo XVIII como puerto estratégico de la corona castellana, especialmente tras la construcción del arsenal hacia la segunda mitad de esta centuria. Igualmente este puerto ocupaba un lugar estratégico en el litoral mediterráneo español, ya que conectaba con Marsella y toda la red mercantil que se integraba con el mercado atlántico y oriental a través de las rutas de Levante. La muestra que hemos usado corresponde a 270 inventarios post mórtem y 66 dotes, en los que, en referencia a los inventarios, hemos seleccionado una prenda masculina (la casaca) y otra femenina (vestidos), y para la muestra de dotes hemos seleccionado ropa de cama (cobertores). La introducción y evolución en el consumo de tales prendas es un indicador crucial para observar cómo nuevas modas penetraron en la sociedad castellana.

A la luz de otras investigaciones (Engel, 2007) podemos señalar que el descenso en el consumo de tales prendas se debió a que la gestión y dirección del mercado de cochinilla en cuanto a precios, promoción del producto y política de distribución y marketing en general no obedecía a una política reglada o de acción conjunta de los agentes comerciales. La distribución de productos tintóreos, tanto a artesanos especializados en teñir como a fabricantes de textiles, estaría relacionada con una red de comerciantes que operaban de manera independiente; a este mercado se lo conoce como polypolistic market o mercado en donde hay una amplia multitud de agentes comerciantes que operan independientemente. Este 
es el caso de los comerciantes de Marsella, y en particular la casa RouxFrères, que actuaban de manera independiente a La Compagnie Française des Indes Orientales. Estas redes de comerciantes no se especializaban en un solo producto, sino en una amplia gama de productos, por lo que no tenían una particular estrategia en la distribución y comercialización de determinados bienes.

En la evolución del consumo de prendas teñidas con grana, tanto de ropa de cama como indumentaria, a partir de los datos de que disponemos vemos una tendencia a la baja para el periodo que abarca de 1770 a 1808 (véanse gráficas 7, 8, 9, 10, 11 y 12), por lo que se podría decir que el declive en el comercio de cochinilla procedente de Nueva España se produciría ya en el último tercio del siglo XVIII, coincidiendo con los datos que presentamos en la gráfica 4 . Hacia la mitad del siglo XVIII, los comerciantes marselleses introducían una gran cantidad de textiles elaborados y semielaborados teñidos de una amplia variedad de tonalidades rojas y granas; introducían entre 5000 y 6000 balas de ropas rojas procedentes de mercados asiáticos a través del Levante (Riello, 2010) y los redistribuían a otros mercados europeos como es el caso de España. Esto evidentemente tenía un efecto negativo en el comercio de grana cochinilla, tal como lo demuestra el descenso secular de este tinte. El colapso de estos mercados, acompañado por la inoperancia de la autoridades de la monarquía española en reglar los centros de producción y redes de comercialización, sería un factor añadido a la preferencia en el consumo de textiles y manufacturas procedentes de mercados asiáticos, en donde las sedas y algodones desplazaron a la lana, tanto castellana como americana, como los materiales preferidos por los consumidores (véanse gráficas 7, 8, 9, 10, 11 y 12).

No en vano, aunque tímidamente, vemos cómo el algodón sustituyó a la lana, tanto la que se producía en suelo peninsular como la americana o lana de vicuña. Hay que contextualizar tal reemplazo dentro del tipo de consumo en el que se sitúan tanto la lana de vicuña como las sedas y los algodones, que en nuestro caso de estudio se sitúan dentro de un consumo conspicuo, propiciado por las clases medias enriquecidas por los negocios. De este modo, aunque la función de los tejidos de lana sea de abrigo y los de seda y algodón ejerzan otras funciones en la vestimenta, hay que situar el consumo de estos tejidos en un clima mediterráneo exento de temperaturas bajas. Por lo tanto, y a la luz de los datos aportados (véanse gráficas $7,8,9,10,11$ y 12), la zona mediterránea del sureste castellano era consumidora de lana y de seda y algodón, especialmente de mercados asiáticos, lo que afectó progresivamente el consumo de lana.

Se trataba pues de textiles de algodón con una amplia variedad cromática que entraban en los mercados del Mediterráneo occidental, Francia y España, a través de las rutas levantinas que conectaban con los pun- 


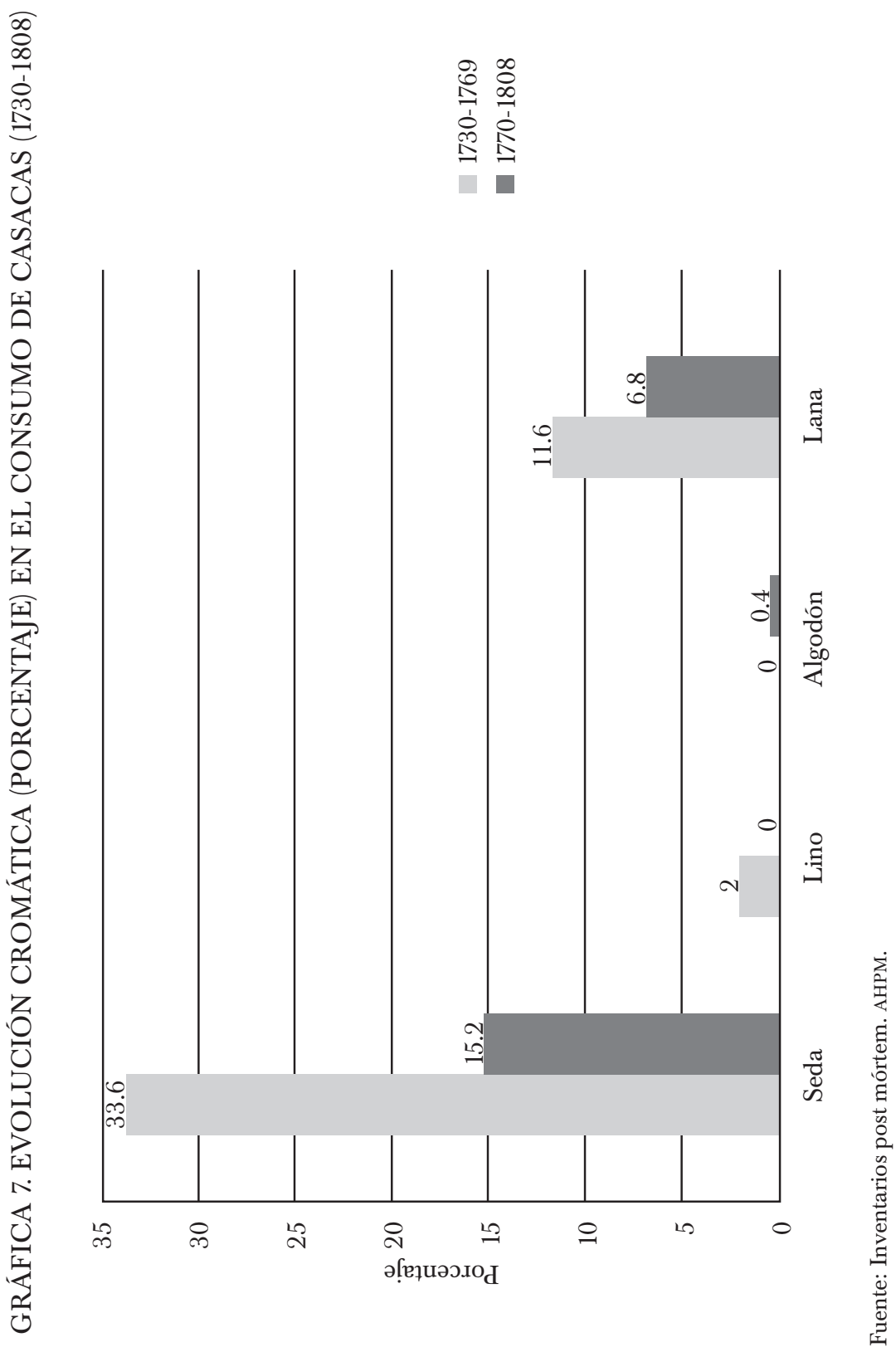




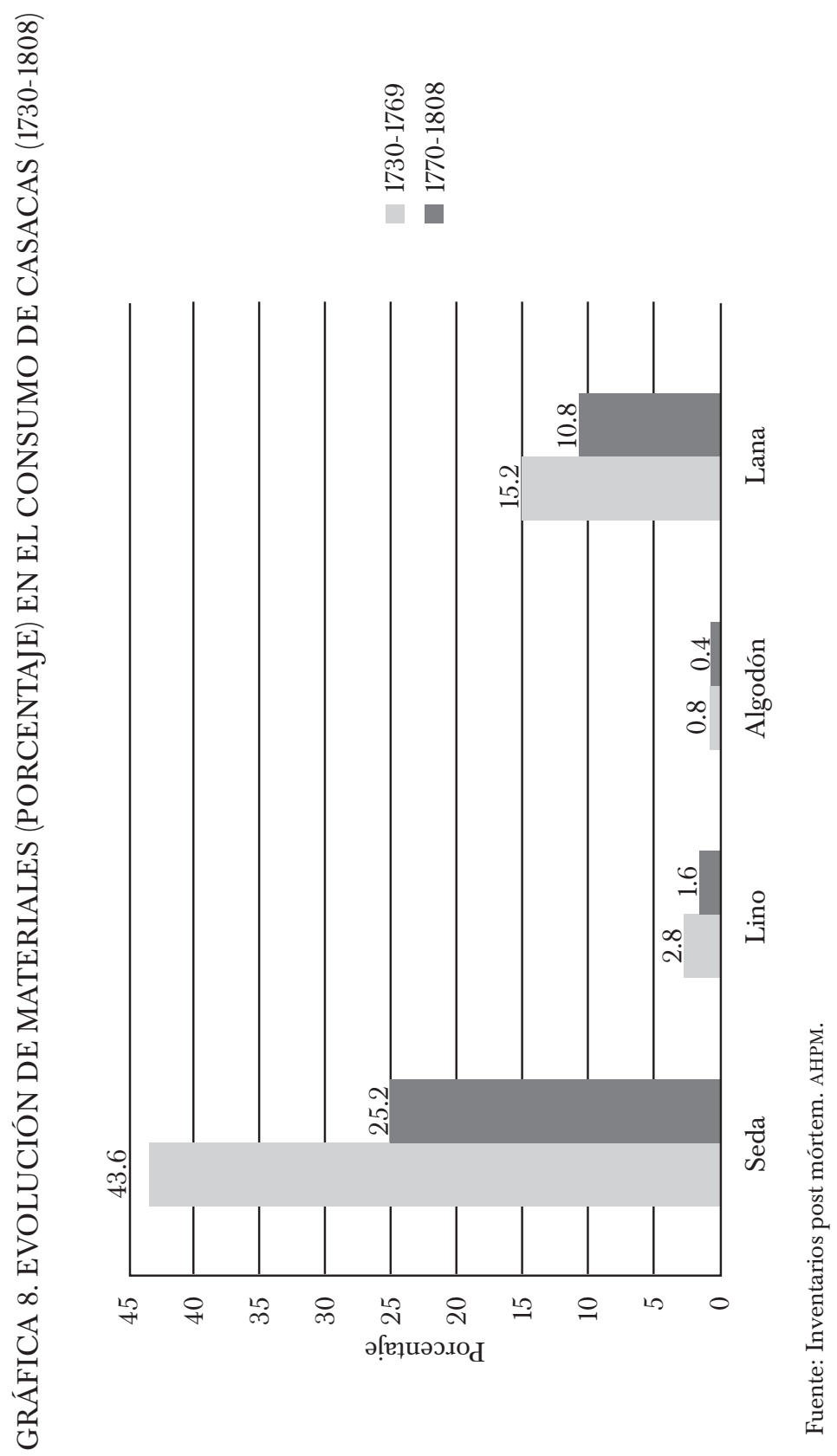




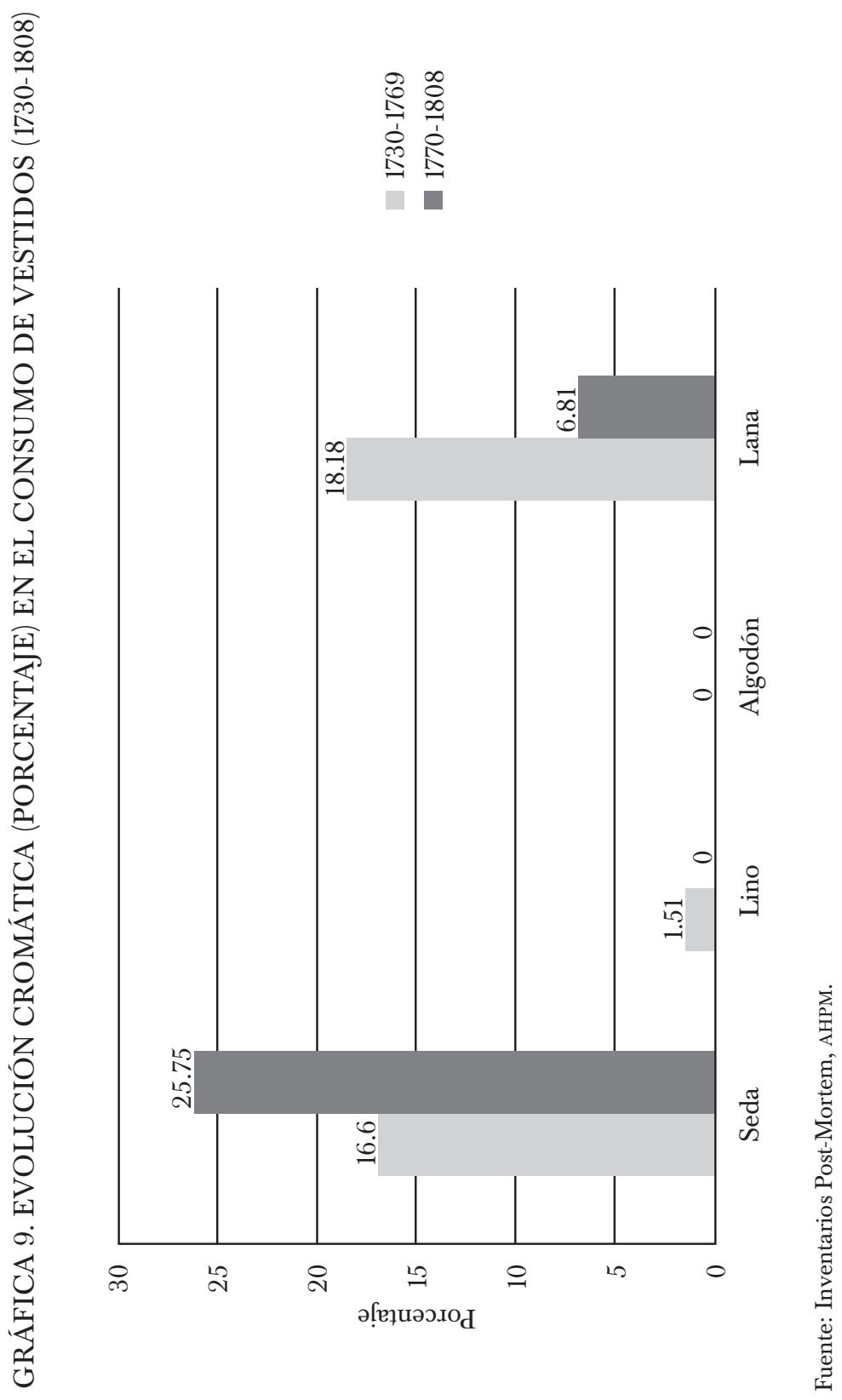




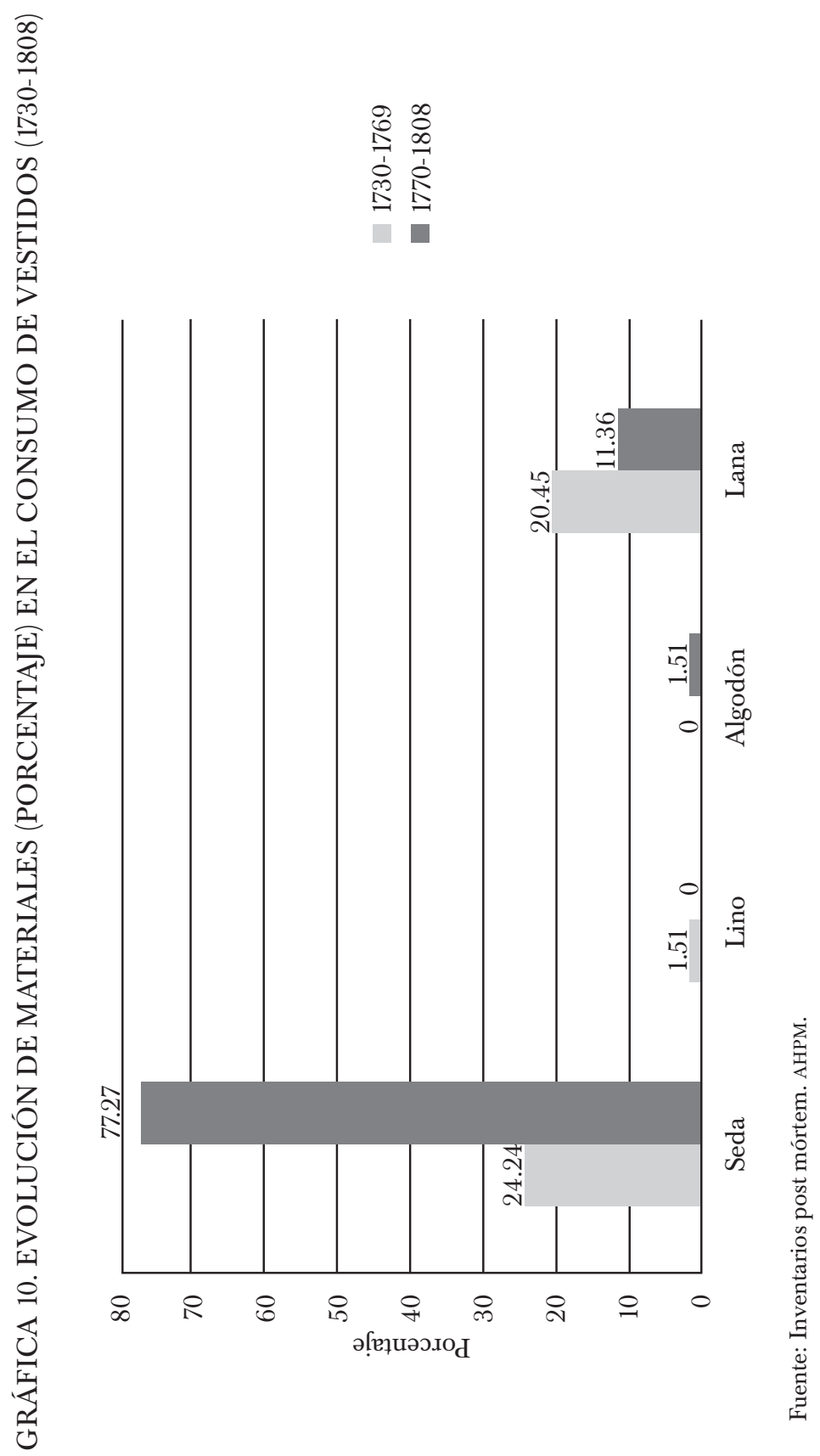




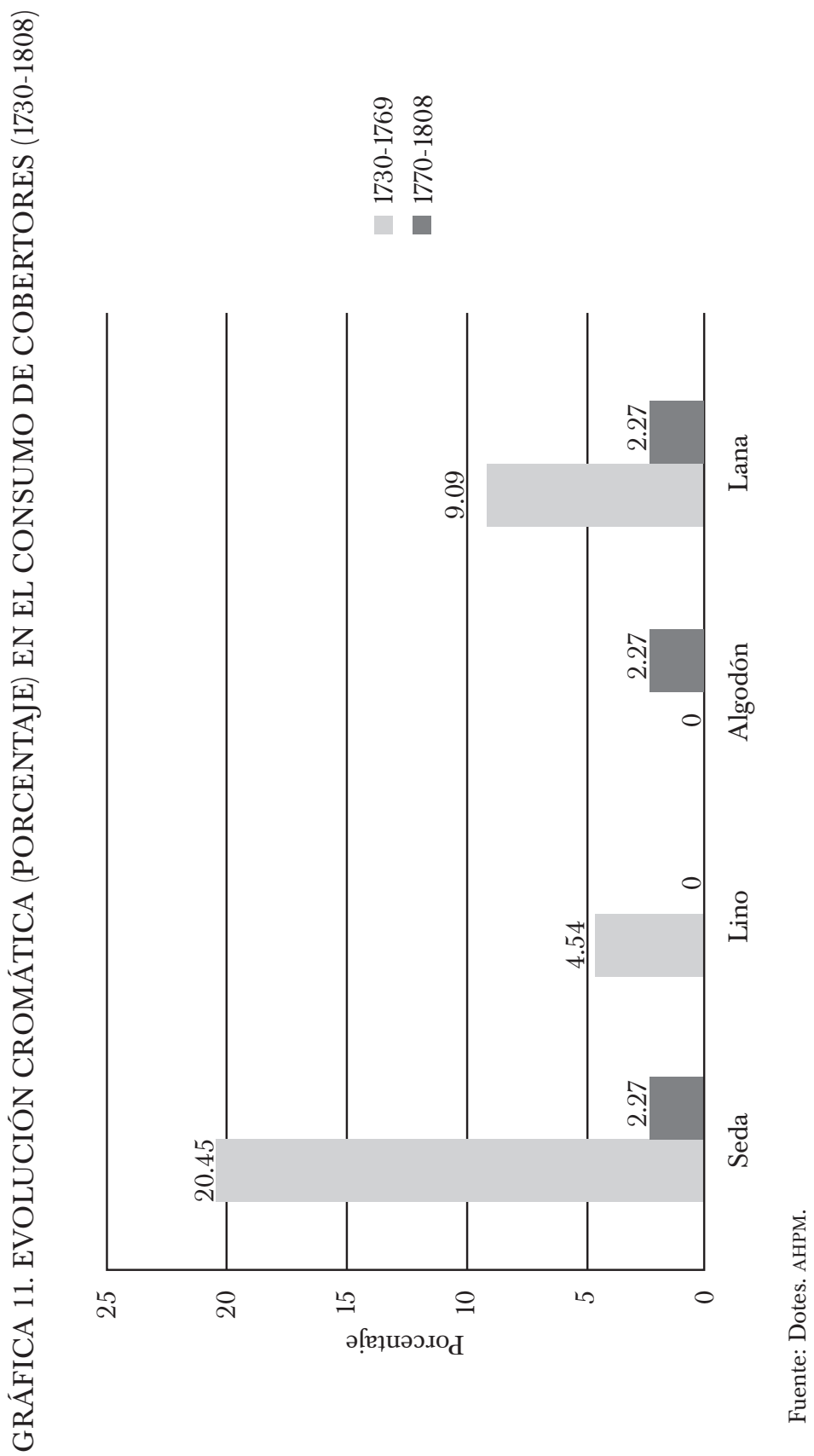




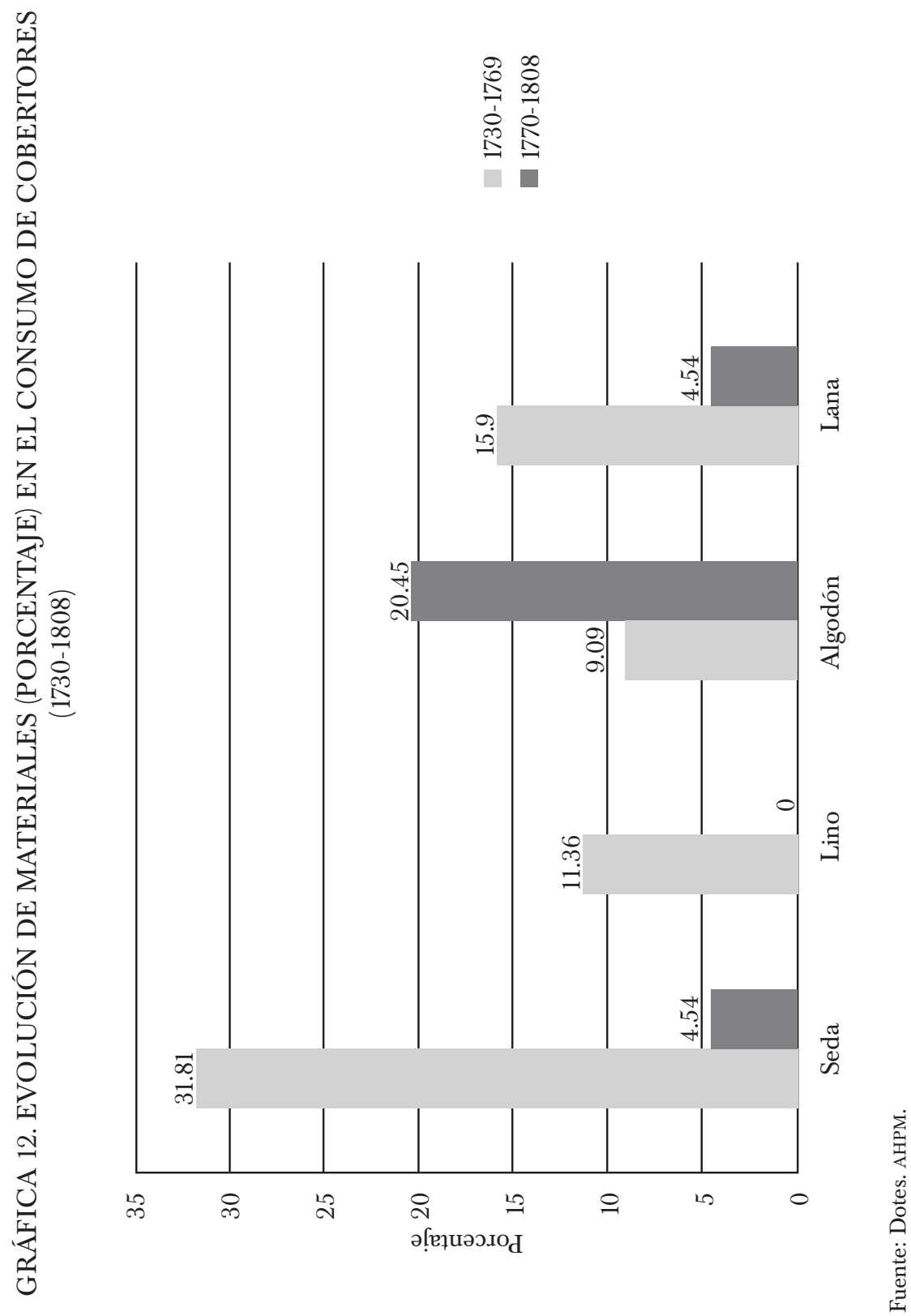


tos estratégicos de Alepo o El Cairo, y que vinculaban o integraban a los mercados de la India y China, siendo los famosos calicoes o indianas (Riello, 2010), así como las sedas de China, los textiles más demandados en Europa durante el siglo XVIII. Puede decirse que el descenso o el estancamiento en el comercio de grana cochinilla y lana de vicuña que se produjo a finales del siglo XVIII e inicios del XIX, se debió a la incapacidad de regular tales mercados por la monarquía española, pero también a la sustitución de bienes que llegaban de mercados asiáticos y que tuvieron un impacto negativo sobre los productos americanos. La especialización unidireccional que tenía la monarquía española en la producción de lana, tanto en territorios peninsulares como en colonias americanas, tuvo una repercusión negativa en el consumo. Esto se debió a que las nuevas modas y tendencias en el consumo estaban fuertemente marcadas por las fibras de algodón y seda. Los complejos métodos de teñido y fabricación hacían que las prendas de algodón y seda fuesen más vistosas, con decoraciones y colores más llamativos que las prendas confeccionadas con lana, cuyos adornos y diseños eran más rudimentarios y toscos.

\section{CONCLUSIONES}

La actividad desempeñada por compañías de comercio internacional, en la cuenca occidental del Mediterráneo, constituyó un factor decisivo en el estímulo de las economías locales de aéreas ribereñas mediterráneas a través del flujo y entrada continua de bienes de consumo procedentes de ultramar. Destaca el puerto de Marsella como centro redistribuidor de mercancías a otros territorios europeos y, en especial, a los puertos mediterráneos españoles. El hecho de que estos territorios tuviesen un bajo potencial industrializador y productor a gran escala de los nuevos bienes demandados por la sociedad española, explica que los consumidores tuviesen que satisfacer sus necesidades a través del comercio extranjero. En otras zonas europeas, en especial en el sur de Francia (Languedoc y Provenza) o en el norte de Italia, en la zona del Piamonte (principalmente en Turín), sí encontramos una industria textil consolidada. En estos centros textiles existía una alta producción de manufacturas cuya finalidad era de alguna forma, en la mayor parte de casos sin mucho éxito, sustituir las importaciones de materias primas, productos semielaborados y acabados procedentes de los mercados atlánticos y asiáticos. Encontrar bienes que sustituyeran a los productos extranjeros, de alta demanda en la sociedad europea, fue un proceso que en primer lugar fue llevado a cabo por Inglaterra. En este caso se trató de buscar bienes para sustituir a las famosas indianas y algodones de la India. En el caso de Holanda los núcleos arte- 
sanales de Delft trataron, sin éxito alguno, copiar y emular las técnicas y procesos de producción de la porcelana china, produciendo los famosos platos y vajillas de Delft. Por lo tanto, buena parte de la sociedad europea, pero especialmente la española, dependía del comercio extranjero para abastecer y satisfacer las nuevas necesidades que se habían insertado en la población, al aparecer un nuevo tipo de consumo más selecto y tendente a cubrir más que las necesidades básicas con nuevos estándares relacionados con el confort y una mayor calidad de vida.

De este modo, la escasez y los bajos niveles de productividad en los centros textiles españoles fueron vistos por los comerciantes y negociantes extranjeros, especialmente los marselleses representados por los Roux, como una oportunidad para encontrar nuevos nichos de mercado y expandir sus redes y actividades mercantiles. Igualmente, la producción de materias primas como sedas, lana, algodón, cochinilla o índigo en territorios de dominio español fue altamente ventajosa para las redes de comercio francesas que instalaron compañías y negocios en territorios y mercados que eran, a priori, de exclusividad de la monarquía española. Un claro ejemplo fue la participación francesa en el comercio de la lana de vicuña peruana y de la cochinilla que se producía en Nueva España, Centroamérica y el virreinato de Perú. Por tanto, el intercambio de materias primas para la elaboración de textiles por productos elaborados o semielaborados, buena parte de ellos manufacturados en centros artesanales de la Francia meridional, fue un factor clave que contribuyó a la lenta modernización del sector textil en la España del siglo XVIII, manteniendo a la larga un saldo negativo en su balanza de pagos. El textil francés más comercializado en América eran las bretañas, así como otros linos tejidos en el norte de Francia. El coste de oportunidad que vislumbraron los comerciantes franceses al establecer redes de comercio en el Mediterráneo que conectaban con mercados de ultramar, resultó clave para el desarrollo y el beneficio de sus negocios, ya que la zona mediterránea de España era un centro geoestratégico de gran importancia para distribuir los productos comercializados no sólo en suelo español sino también hacia otras zonas europeas. El éxito del establecimiento y fortalecimiento de tales redes de comercio se debió, en buena medida, a la expansión de sus negocios con la comunidad extranjera en aquellos lugares donde se asentaban. Dicha comunidad tenía su actividad económica tanto en los mercados mediterráneos de España como al otro lado del Atlántico. Por lo tanto, se creó, una comunidad extranjera interconectada a través de los negocios y la actividad comercial.

La comercialización de productos elaborados a partir de materias primas procedentes de suelo español y de las colonias de América manufacturados en las industrias textiles francesas e italianas, es un factor altamen- 
te representativo de las conexiones a escala internacional y global que se establecían en el mercado mediterráneo, especialmente conectado con las rutas del Atlántico. Las regiones costeras españolas, como el puerto de Cartagena, localizado en el sureste, participaron en este mercado global donde la divergencia económica entre economías con suficiente capacidad de producción, como las mencionadas del sur de Francia y norte de Italia, y otras que dependían de la financiación y producción externa, como el caso de la propia Cartagena, llegó a ser un hecho cada vez más obvio. A través del análisis de los registros en la Chambre de Commerce de Marseille, la dependencia de la economía española resulta bastante evidente. Mediante el estudio de la continua entrada de productos extranjeros, especialmente pertenecientes al sector textil, nos hemos podido percatar de que la población española se sintió atraída por nuevos bienes exóticos, relacionados con un consumo más selecto, procedentes de ultramar. La alta comercialización de materias primas que procedían de las colonias españolas americanas relacionadas con el sector textil es una prueba notable de dicha atracción.

\section{LISTA DE REFERENCIAS}

AlZATE, J. A. DE [1777] (2005). Memoria sobre la naturaleza, cultivo y beneficio de la grana. La grana y el nopal en los textos de Alzate. México: Consejo Nacional para la Cultura $\mathrm{y}$ las Artes.

Arrioja, L. A. (2013). El cultivo de la grana en el sur de México, 1752-1856. Baetica. Estudios de Arte, Geografia e Historia, 35, 253-270.

ÁvilA, A. (2001). Grana cochinilla, insecto humanizado. Biología y mexicanidad en los textos de Alzate y sus contemporáneos acerca de la grana. En Memoria sobre la naturaleza, cultivo y beneficio de la grana. México: Archivo General de la Nación.

BASKES, J. (2000). Indian, merchants and markets. A reinterpretation of the repartimiento and Spanish-Indian economic relations in colonial Oaxaca, 1750-1821. Stanford: Stanford University Press.

BeEson, K. H. JR. (mayo, 1964). Indigo production in the eighteenth century. The Hispanic American Historical Reviewe, 44(2), 214-218.

Benavente, T. De [Motolinía] (1941). Historia de los indios de Nueva España. México: Salvador Chávez de Hayhoe.

Bonialian, M. (2012). El Pacífico hispanoamericano. Política y comercio asiático en el imperio español (1680-1784). México: El Colegio de México.

Born, W. (marzo, 1938). Scarlet. Ciba Reviere, 7, 205-227.

Boxer, C. R. (julio, 1970). Plata es sangre: Sidelights on the drain of Spanish-American silver in the Far East, 1550-1700. Philippines Studies, 18(3), 457-478. 
BRAUdel, F. (1979). Civilisation matérielle, économie et capitalisme, XVe-XVIIIe siècle (3 vols.). París: Armand Colin.

Brown, V. L. (mayo, 1928). Contraband trade: a factor in the decline of Spain's empire in America. The Hispanic American Historical Review, 8(2), 178-189.

CARrière, CH. (1973). Négociants marseillais au XVIIIe siècle. Contribution à l'étude des économies maritimes (2 vols.). Marsella: Institut Historique de Provence.

Chaudhuri, S. (1997). World silver flows and monetary factors as a force of international economic integration, 1658-1758. En D. FlYnN y A. GiráldEZ (coords.), Metals and monies in an emerging global economy (pp. 61-79). Hampshire: Variorum.

Chaudhury, S. y Morineau, M. (eds.) (1999). Merchants, companies and trade: Europe and Asia in the early modern era. Londres y Nueva York: Cambridge University Press.

Christelow, A. (noviembre, 1941). French interest in the Spanish empire during the ministry of the Duc de Choiseul, 1759-1771. The Hispanic American Historical Review, 27(4), 515-537.

Cuenca, J. J. (2004). Comparative patterns of colonial trade: Britain and its rivals. En L. Prados (ed.), Exceptionalism and industrialization: Britain and its European rivals, 1688-1815 (pp. 35-66). Cambridge: Cambridge University Press.

Dalhgren, B. (1990). La grana cochinilla. México: Universidad Nacional Autónoma de México.

DAVIS, R. (1967). Aleppo and Devonshire Square. English traders in the Levant in the eighteenth century. Londres: McMillan.

Donkin, R. A. (1977). Spanish red: an ethnographic study of cochineal and the Opuntia cactus. Transactions of the American Philosophical Society, 67(5), 1-84.

ENGEL, A. (2007). From traditional networks to modern companies. The transition of the markets for dyestuffs in the 19th century. 11th Annual Conference, European Business History Association, Geneva.

Escandel, N. (1997). Producción y comercio de tejidos coloniales. Los obrajes y chorrillos del Cusco. Cusco: Editorial Bartolomé de Las Casas.

ESCOBARI, L. (2014). Producción y comercio en la historia de Bolivia colonial s. XVI-XVIII (2a ed.). La Paz: Ed. Plural/Instituto de Estudios Bolivianos/Universidad Mayor de San Andrés.

FAbrégas, J. (2005). El primer año de libre comercio en Cataluña. En C. Martínez y J. M. Oliva (eds.), El sistema atlántico español (siglos XVII-XIX) (pp. 285-310). Madrid: Marcial Pons.

FERnÁNDEZ, L. M. (1996). Exportación de lanas, trashumancia y ocupación del espacio en Castilla durante los siglos XVI, XVII y XVIII. En P. García y J. M. SÁnchez (eds.), Contribución a la historia de la trashumancia en España (pp. 343-362). Madrid: Ministerio de Agricultura, Pesca y Alimentación.

Fisher, J. (mayo, 1985a). The imperial response to "free trade": Spanish imports from Spanish America, 1778-1796. Journal of Latin America Studies, 17(1) 35-78. 
FISHER, J. (1985b). Commercial relations between Spain and Spanish America in the era of free trade 1778-1796. Liverpool: University of Liverpool.

FLOYD, S. T. (invierno, 1965). The indigo merchants: Promoter of Central American economic development, 1750-1808. The Business Historic Review, 39(4), 466-488.

FLynN, D. y GiráldEZ, A. (2002). Cycles of silver: Global economic unity through the mid-eighteenth century. Journal of World History, 13(2), 391-427.

FriIS, A. (1927). Alderman cockayne's project and the cloth trade. Londres: Oxford University Press.

GARCÍA, A. (1989). La política agraria ilustrada y sus realizaciones. En Estructuras agrarias y reformismo ilustrado en la España del siglo XVIII (pp. 629-638). Madrid: Ministerio de Agricultura, Pesca y Alimentación.

GarcíA, L. (1980). El comercio español con América (1650-1700). Sevilla: Diputación Provincial de Sevilla.

Gerhard, H. J. y Kaufhold, K. H. (eds.) (2001). Preise im vor- und frühindustriellen Deutschland. Nahrungsmittel-Getränke-Gewürze. Stuttgart: Rohstoffe und Gewerbeprodukte.

Hamnett, B. (1971). Politics and trade in Southern México, 1750-1821. Cambridge: Cambridge University Press.

Haupt, H. G. y KockA, J. (eds.) (2009). Comparative and trans-national history. Nueva York: Berghahn Books.

Houghton, H. (1887). La cochinilla. Memoria demostrativa de las causas que han producido la decadencia de este renglón de comercio en los últimos años. [Publicada por la Sociedad Económica de Amigos del País de Gran Canaria]. Gran Canaria: Imprenta de la Verdad.

Hudson, P. (2008). The limits of wool and the potential cotton in the eighteenth and early nineteenth centuries. En G. Riello y P. Parthasarathi (eds.), The spinning world. A global history of cotton textiles, 1200-1850 (pp. 327-350). Londres: Oxford University Press.

Koford, C. B. (abril, 1957). The vicuna and the puna. Ecological Monographs, 27(2), 153-219.

LARRÈRE, C. (1992). L'invention de l'economie au XVIIIe siècle du droit naturel á la physiocratie. París: Prosses Universitaires de France.

LEE, R. L. (abril, 1948). Cochineal production and trade in New Spain to 1600. The Americas, 4(4), 449-473.

Lemeunier, G. y Pérez, M. T. (1990). Les français en Murcie sous l'Ancien Régime (v.1700-v.1850). Des migrations populaires au grand commerce. En Les Français en Espagne a l'époque moderne (XVIe.-XVIIIe. Siècles). París: Centre National de la Recherche Scientifique.

Lemire, B. (2008). Revising the historical narrative: India Europe, and the cotton trade, c. 1300-1800. En G. Riello y P. Parthasarathi (eds.), The spinning world. A global history of cotton textiles, $1200-1850$ (pp. 206-226). Londres: Oxford University Press. 
Malamud, C. (1981). El comercio directo de Europa con América en el siglo XVIII. Algunas consideraciones. Quinto Centenario, 1, 25-52.

Malamud, C. (1983). El comercio colonial del siglo XVIII visto como suma del comercio vía Andalucía y del comercio directo europeo. Journal of Iberian and Latin American Economic History, 1(2), 307-322.

MARICHAL, C. (2006a). The Spanish American silver peso: export commodity and global economy of the Ancient Regime $\left(16^{\text {th }}-18^{\text {th }}\right.$ centuries $)$. En S. ToPIK, C. MARICHAL y Z. FRANK (coords.), From silver to cocaine: Latin American commodity chains and the building of a world economy, 1500-2000 (American Encounters/Global Interactions) (pp. 25-52). Durham: Duke University Press.

Marichal, C. (2006b). Mexican cochineal and the European demand for American dyes, 1550-1850. En S. TOPIK, C. MARICHAL y Z. Frank (coords.), From silver to cocaine: Latin American commodity chains and the building of a world economy, 15002000 (American Encounters/Global Interactions) (pp. 76-92). Durham: Duke University Press.

Martín, E. (2008). Marseille, échelle des toiles levantines pour l'Espagne, XVIIe et XVIIIe siècles. Rives Méditerranéennes, 29, 61-78.

Martínez, C. (1992). Comercio colonial ilustrado y periferia metropolitana. Rábida, 11 , pp. 58-72.

MCCusKer, J. y Gravesteijn, C. (1991). The beginnings of commercial and financial journalism: The commodity price currents, exchange rate currents, and money currents of early modern Europe. Ámsterdam: Netherlands Economic History Archives.

O'Brien, P. (2000). Mercantilism and imperialism in the rise and decline of the Dutch and British empire, 1688-1815. De Economist, 148(4), 469-501.

Oliva, J. M. y MARTínez, C. (2005). El sistema atlántico español (siglos XVII-XIX): presentación. En C. Martínez y J. M. Oliva (eds.), El sistema atlántico español (siglos $X V I I-X I X)$ (pp. 11-18). Madrid: Marcial Pons.

OrTiz, M. (2010). Historia e historiografía de la grana cochinilla (Dactylopius Coccus) como recurso natural en el México virreinal (Tesis doctoral). Universidad Nacional Autónoma de México, México.

PANZAC, D. (2004). La caravane maritime. Marins européens et marchands ottomans en Méditerranée (1680-1830). París: Centre National de la Recherche Scientifique.

PÉrez, M. (2013). "Vicarious Consumers": Trans-national meetings between the West and East in the Mediterranean world (1730-1808). Londres: Ashgate.

RaveAux, O. (2008). The birth of a new European industry: L'Indiennage in seventeenth-century Marseilles. En G. Riello y P. PARTHASARATHi (eds.), The spinning world. A global history of cotton textiles, 1200-1850 (pp. 291-306). Londres: Oxford University Press.

Riello, G. (marzo, 2010). Asian knowledge and the development of calico printing in Europe in the seventeenth and eighteenth centuries. Journal of Global History, 5(1), 1-28. 
Riello, G. (2013). Cotton: The fabric that made the modern world. Cambridge: Cambridge University Press.

Ringrose, D. (1973). European economic growth: Comments on the North-Thomas Theory. The Economic History Review, 26(2), 285-292.

Ringrose, D. (1996). Spain, Europe and the "Spanish miracle", 1700-1900. Cambridge: Cambridge University Press.

Roche, D. (1989). La culture des apparences. Une histoire du vêtement XVIIe-XVIIIe siècle. París: Fayard.

SAlas, J. A. (2009). En busca del dorado: inmigración francesa en la España de la edad moderna (pp. 214-224). Bilbao: Universidad del País Vasco.

SAlas, M. (1998). Estructura colonial del poder en el Perú: Huamanga a través de sus obrajes. Lima: Pontificia Universidad Católica del Perú.

SÁnchez, C. y SuÁrez, M. (2006). Evolución de la producción y el comercio mundial de la grana cochinilla, siglos XVI-XIX. Revista de Indias, 56(237), 473-490.

SMith, R. S. (mayo, 1959). Indigo production and trade in colonial Guatemala. The Hispanic American Historical Review, 39(2), 181-211.

SousA, L. DE (2010). The early European presence in China,Japan, the Philippines and Southeast Asia (1555-1590). The life of Bartolomeu Landeiro. Macau: Macau Foundation.

Stein, S. J. y Stein, B. (2003). Apogee of empire. Spain and New Spain in the age of Charles III. Baltimore and Londres: John Hopkins University Press.

UllOA, A. DE (1772). Noticias americanas: entretenimientos phísicos históricos. Madrid: Impr. de Don Francisco Manuel de Mena.

VALLe, G. DEL (1992). El camino México-Puebla-Veracruz: comercio poblano y pugnas entre mercaderes a fines de la época colonial. México: Gobierno del Estado de Puebla/Secretaría de Gobernación/Archivo General de la Nación.

VAlle, G. DEL (2011). Cádiz y México, núcleos mercantiles en la Carrera de Indias, siglos XVII y XVIII. Revista Digital. Real Academia Hispano Americana de Ciencias, Artes y Letras, 1. Recuperado de http://revista.raha.es/mercaderes.html

Walker, G. (1979). Política española y comercio colonial, 1700-1789. Barcelona: Ariel.

Wiedner, D. L. (abril, 1960). Forced labor in colonial Peru. The Americas, 16(4), 357-383.

\section{OTRAS FUENTES}

\section{Archivos}

ACCM Archive de la Chambre de Commerce de Marseille, Marsella, Francia.

AHPM Archivo Histórico Provincial de Murcia, Murcia, España. 